\title{
High-temperature creep rupture of low alloy ferritic steel butt-welded pipes subjected to combined internal pressure and end loadings
}

DOI:

10.1098/rsta.2005.1583

Link to publication record in Manchester Research Explorer

Citation for published version (APA):

Vakili-Tahami, F., Hayhurst, D., \& Wong, M. (2005). High-temperature creep rupture of low alloy ferritic steel buttwelded pipes subjected to combined internal pressure and end loadings. Philosophical Transactions of the Royal Society A: Mathematical, Physical and Engineering Sciences, 363, 2629-2661. https://doi.org/10.1098/rsta.2005.1583

Published in:

Philosophical Transactions of the Royal Society A: Mathematical, Physical and Engineering Sciences

\section{Citing this paper}

Please note that where the full-text provided on Manchester Research Explorer is the Author Accepted Manuscript or Proof version this may differ from the final Published version. If citing, it is advised that you check and use the publisher's definitive version.

\section{General rights}

Copyright and moral rights for the publications made accessible in the Research Explorer are retained by the authors and/or other copyright owners and it is a condition of accessing publications that users recognise and abide by the legal requirements associated with these rights.

\section{Takedown policy}

If you believe that this document breaches copyright please refer to the University of Manchester's Takedown Procedures [http://man.ac.uk/04Y6Bo] or contact uml.scholarlycommunications@manchester.ac.uk providing relevant details, so we can investigate your claim.

\section{OPEN ACCESS}




\title{
High-temperature creep rupture of low alloy ferritic steel butt-welded pipes subjected to combined internal pressure and end loadings
}

\author{
By F. Vakili-Tahami, D. R. Hayhurst and M. T. Wong \\ Department of Mechanical, Aerospace and Civil Engineering, The University of \\ Manchester, Manchester, M60 1QD, UK \\ (d.r.hayhurst@manchester.ac.uk)
}

Constitutive equations are reviewed and presented for low alloy ferritic steels which undergo creep deformation and damage at high temperatures; and, a thermodynamic framework is provided for the deformation rate potentials used in the equations. Finite element continuum damage mechanics studies have been carried out using these constitutive equations on butt-welded low alloy ferritic steel pipes subjected to combined internal pressure and axial loads at 590 and $620^{\circ} \mathrm{C}$. Two dominant modes of failure have been identified: firstly, fusion boundary failure at high stresses; and, secondly, Type IV failure at low stresses. The stress level at which the switch in failure mechanism takes place has been found to be associated with the relative creep resistance and lifetimes, over a wide range of uniaxial stresses, for parent, heat affected zone, Type IV and weld materials. The equi-biaxial stress loading condition (mean diameter stress equal to the axial stress) has been confirmed to be the worst loading condition. For this condition, simple design formulae are proposed for both 590 and $620{ }^{\circ} \mathrm{C}$.

Keywords: high-temperature; creep rupture; welds; CDM

\section{Introduction}

Design codes (BS 1113, British Standards Institution 1989; BS 5500, British Standards Institution 1991; BS 806, British Standards Institution 1993) for hightemperature pressurized welded pipes are based on the uniaxial stress rupture properties of the parent pipe material, and do not account for the effects of the multiaxial stress states which arise from the different mechanical properties of the parent material, weld material and the associated phases. In these codes, the pipe wall thickness, $\hat{t}$, is determined from the thin pressure vessel formulae for the mean diameter hoop stress

$$
\sigma_{\mathrm{mdh}}=P_{\text {int }} D_{\mathrm{m}} / 2 \hat{t},
$$

where $D_{\mathrm{m}}\left(=D_{\text {in }}+\hat{t}\right)$ is the mean diameter and, $D_{\text {in }}$ and $P_{\text {int }}$ are internal diameter and pressure, respectively. Due to these limitations, creep failure in weldments can occur earlier than the expected rupture time.

One contribution of 7 to a Theme Issue 'Thermodynamics in solids mechanics'. 
In an attempt to overcome this shortcoming, Hall \& Hayhurst (1991) developed a continuum damage mechanics (CDM) based finite element (FE) solver, DAMAGE XX, which incorporates the physics of the creep deformation and rupture of the individual phases of the weld materials. This approach has been shown to predict successfully the deformation, damage and failure history of the full-size pressure vessel weldment tests of Coleman et al. (1985). The research highlighted the important role of the difference in the creep characteristics of the weld metal, the heat affected zone (HAZ) material, and the parent material. It was shown that the mismatch between material phases results in a marked redistribution of stress from the weld metal into the HAZ and the parent material. It was also shown that the location of the maximum axial and hoop stresses shifts from the inner surface to the outer surface in all micro-structural regions of the weld during primary-secondary creep. This leads to the initiation and evolution of creep damage in the outer third of the weld metal and the HAZ that is in the region known as fusion boundary (FB). It was also observed that during the secondary creep stage, the maximum effective stress occurs at the inner surface of the pipe and, the maximum principal stress occurs at the outer surface. Hence, the multiaxial stress rupture criterion, $\alpha$, has an important role in further stress redistribution, the determination of the damage distribution, and the predicted lifetime. And, depending upon the value of the multiaxial stress rupture criterion, the weldment can show either strengthening or weakening relative to the behaviour of the material phase in which failure occurs. Hayhurst, Dimmer, \& Morrison (1984) have also observed this phenomenon in the estimation of the creep rupture times for notched bars. In order to investigate the effect of the material properties on the rupture time of butt-welded pressure vessels, Wang \& Hayhurst (1994) have used the FE CDM solver, DAMAGE XX, to carry out studies on the weldment lifetimes for different combination of mechanical properties of the weld and HAZ materials. At least forty different low alloy ferritic steel butt-welded pressure vessels were analysed for a constant internal pressure and temperature with the same parent material but with different creep characteristics for the weld and HAZ materials. To this end, a set of normalized material parameters were introduced to define the creep behaviour of the weld metal and the HAZ material relative to the parent metal. The introduction of the normalized material parameters permitted the determination of the constants in the constitutive equations (Wang \& Hayhurst 1994). From these studies, it was concluded that an optimal set of weld and HAZ material properties exists which results in an improvement in the lifetime prediction of $30 \%$ over that obtained for the initial material property data set. Hence, CDMbased FE methods have been found to be a valuable tool for the analysis of the creep rupture behaviour of the pipe weldments. They may also be used to establish a methodology for the design of weldments.

To reduce cost, and improve speed, approximate methods have also been proposed by Perrin et al. (2000) for the analysis of butt-welds. This method is based on the modal method developed by Leckie \& Hayhurst (1974), which is used to compute the creep rupture lifetime of kinematically determinate structures; this category includes butt-welded internally pressurized pipes. Lifetimes predicted using the modal method have been found to be conservative, on average by $14 \%$, when compared to lifetimes determined using CDM analyses. In addition, the modal method accurately predicts the regions of intense damage. 
It assumes: kinematical determinacy; no damage is accumulated in reaching a stationary state; and the time to achieve a stationary state is not a significant fraction of the component lifetime. The above assumptions limit the application of the method up to the time at which the first failure occurs. Inspite of this, the method provides a fast, accurate and simple means for the estimation of the rupture lifetimes for weldments. Since this method accounts for stress redistribution within the weldment due to the different creep properties of the weld and HAZ materials, and to the multiaxial stress rupture criterion of each material, it gives more reliable results when compared with other approximate methods which are based on the reference stress analysis techniques.

Hayhurst \& Miller (1998) have used CDM-based constitutive equations to model the behaviour of the weld, HAZ, Type IV and parent material in a low alloy ferritic steel weldment operated at $590{ }^{\circ} \mathrm{C}$ in a welded pressure vessel connection. They used the equations in DAMAGE XX, to model the creep deformation and multiaxial rupture behaviour of weldments in the axisymmetric equivalents of the Crotch and Flank sections of pressurized pipe work branch connections. It was shown that the Crotch section fails in the Type IV region adjacent to the branch, whilst the Flank section fails in the Type IV zone close to the sphere (main pipe). This is due to the low effective stress and high first stress invariant in these regions which themselves are a result of stress redistribution caused by the mismatch in the creep properties of the weld, HAZ, Type IV and parent materials. The results of these CDM analyses have yet to be compared with the results of vessel tests which are currently in progress.

In recent years, a number of experimental studies have investigated the hightemperature creep failure mechanisms for the weldments in ferritic steel steam pipework. These investigations have shown that most high-temperature creep failures take place by the growth of circumferential creep cracks in the HAZ region, adjacent to the parent material. This zone, known as the Type IV region (Gooch \& Kimmins 1987; Perrin \& Hayhurst 1999), experiences the lowest temperatures during the welding process which are in the range $850-900{ }^{\circ} \mathrm{C}$. At these temperatures, significant coarsening and incomplete dissolution of the carbide precipitates takes place together with the refinement of grain size which, in turn, leads to a significant loss of creep resistance of the metal. CDM techniques have been used by Perrin \& Hayhurst (1999) to model the deformation and the failure of weldments which fail within the Type IV region. They analysed the creep behaviour of homogenous and circumferencially welded notched bars to determine the values of the multiaxial stress rupture criterion of the Type IV material. The resulting mechanism-based constitutive equations were used in the CDM-based FE solver, DAMAGE XX, to predict the deformation and rupture of a uniaxially loaded crossweld specimen. The computational predictions were shown to be, quantitatively and qualitatively, in good agreement with the experimental results (Perrin \& Hayhurst 1999).

CDM-based creep analyses of the butt-welded low alloy ferritic steel pipes have been carried out by Hayhurst \& Perrin (1995) to overcome two major shortcomings of the pioneering work carried out by Hall \& Hayhurst (1991). These are firstly, the neglect of the Type IV region of the weldment; and, secondly the deficiencies of using a single damage state variable. Hence, a set of constitutive equations was introduced which incorporated two state variables: the first, $\omega$, to model the creep cavitation; and, the second, $\Phi$, to model the 
coarsening of carbide precipitates. This set of constitutive equations was then used to perform FE creep CDM analyses to predict the failure of the butt-welded pipe subjected to the combined internal pressure and independent end loads at the operating temperature of $620^{\circ} \mathrm{C}$. It was shown that the presence of the end load tends to invoke Type IV failure. Hayhurst \& Perrin (1995) considered two loading conditions: firstly, a pure internal pressure, which generates stress on the end caps of the vessel with the ratio $\sigma_{\text {mdh }} / \sigma_{\text {axial }}=2$; and, secondly, a combined internal pressure and additional end load, which results in the ratio of $\sigma_{\mathrm{mdh}} /$ $\sigma_{\text {axial }}=1$. In the remainder of this paper reference is made to the former condition, $\sigma_{\mathrm{mdh}} / \sigma_{\text {axial }}=2$, for tubes subjected to internal pressure only. This statement is valid for thin tubes; but is an approximation for thick tubes. The latter case was selected since it is an extreme condition considered in design codes. The magnitudes of these loadings were selected to give the same lifetime of $60000 \mathrm{~h}$ in each case when the pipe is constructed entirely of the parent material (no weldment). Hayhurst \& Perrin (1995) showed that for the welded pipe under pure internal pressure $\left(\sigma_{\mathrm{mdh}} / \sigma_{\text {axial }}=2\right)$, creep damage initiates and evolves along the FB as a macro-crack in a time of $50000 \mathrm{~h}$. Hall \& Hayhurst (1991) have previously observed this type of failure for similar conditions. For the second loading condition $\left(\sigma_{\mathrm{mdh}} / \sigma_{\text {axial }}=1\right)$, it was observed that creep damage initiates and grows from outer surface along the Type IV region, and forms a creep crack in a lifetime of $27000 \mathrm{~h}$. The research led to the conclusion that there is a need to accurately characterize the different failure modes and their interplay with respect to the different loading conditions in low alloy ferritic steel butt-welded pressure pipes. Hence, the objectives of this paper are: firstly, to understand and to predict the creep behaviour and failure mechanisms of low alloy ferritic steel weldments for different loading and temperature conditions; and, secondly, to characterize the interplay between different failure modes with respect to the operating temperature, loading conditions and, stress level. An understanding of such conditions will enable the proposal of a set of simple and easy to use design equations which will provide a conservative lifetime for welded pipes as a function of internal pressure and end loadings.

\section{Outline of the investigation}

In this paper, the creep deformation and failure of a low alloy ferritic steel buttwelded pressure steam pipe has been analysed using the FE CDM-based solver, DAMAGE XX. A low alloy steel combination of $0.5 \mathrm{Cr} 0.5 \mathrm{Mo} 0.25 \mathrm{~V}$ pipe welded with $2.25 \mathrm{Cr} 1 \mathrm{Mo}$ weld metal, which have been used extensively in steam pipework in fossil fired and nuclear power stations, have been selected for this study. Two operating temperatures of 590 and $620^{\circ} \mathrm{C}$ have been selected to take into account the effect of the temperature level on the creep behaviour of the different material phases in the weldment. In addition, to understand the interplay between the different failure modes, a wide range of internal pressures and independent end loads have been used: $0 \leq\left(\sigma_{\text {mdh }} / \sigma_{\text {axial }}\right) \leq \infty$, which include two design code conditions of practical interests: $\sigma_{\text {mdh }} / \sigma_{\text {axial }}=2$ and $\sigma_{\text {mdh }} / \sigma_{\text {axial }}=1$.

Two different sets of CDM-based constitutive equations have been employed to describe the creep behaviour of the low alloy ferritic steel parent material and of each material zone of the weldment at the two operating temperatures. 
For $590{ }^{\circ} \mathrm{C}$, the hyperbolic-sine stress sensitivity equations (Perrin \& Hayhurst 1999) have been used. And at $620^{\circ} \mathrm{C}$, the Norton power law stress sensitivity equations has been used (Coleman et al.1985; Hayhurst \& Perrin 1995). Each set of constitutive equations incorporate two state variables: one which models the creep constrained cavitation, $\omega$; and the other which models the coarsening of the carbide precipitates, $\Phi$.

The objectives of this paper are to:

(i) review the creep constitutive equations used for low alloy ferritic steels, and provide a thermodynamic framework for the deformation rate potentials used in the equations;

(ii) categorize those loading conditions which determine Type IV and FB failures;

(iii) understand the interplay between these two failure modes;

(iv) appreciate the underlying/controlling physics which dictate each particular failure mode;

(v) predict the creep lifetimes of weldments using CDM; and

(vi) propose or justify simplified design/analysis methods which provide a reasonably conservative estimation of the lifetime as a function of internal pressure.

In $\S 3$, the CDM-based constitutive equations will be presented which will be used to characterize the creep deformation and rupture behaviour of each distinct material region.

\section{Constitutive equations for creep without damage}

\section{(a) Uniaxial relations}

Following Bailey (1929, 1935) and Odqvist (1974), it will be assumed that hightemperature creep takes place without change in volume of the material. Two uniaxial laws are considered here; firstly the $n$-power creep law due to Norton (1929)

$$
\frac{\mathrm{d} \varepsilon}{\mathrm{d} t}=\dot{\varepsilon}=G \sigma^{n} t^{m},
$$

where $G$ and $n$ are materials constants at a given temperature and $m$ is the index introduced by Andrade $(1910,1914)$ to describe time hardening encountered in primary creep. The second creep law is the hyperbolic-sine law (Garofalo 1963)

$$
\frac{\mathrm{d} \varepsilon}{\mathrm{d} t}=A \sinh \left(B \sigma_{\mathrm{e}}(1-H)\right),
$$

where $A$ and $B$ are material constants at a given temperature. The parameter $H$ is a state variable used to model the change of dislocation density during primary creep. When the material enters secondary creep, $H$ takes its saturation value $H^{*}$. Equation (3.1) is used to model creep behaviour over narrow ranges of stress while equation (3.2) is frequently used to model creep behaviour from stresses close to zero, to stress levels in excess of the first, time independent, yield stress. 


\section{(b) Multiaxial relations}

(i) n-Power law

Odqvist (1934) has generalized equation (3.1) to multiaxial conditions using the scalar potential function

$$
\Psi=\frac{G}{(n+1)} \sigma_{\mathrm{e}}^{n+1} t^{m},
$$

where the effective stress, $\sigma_{\mathrm{e}}$, is given by $\sigma_{\mathrm{e}}^{2}=\left(3 s_{i j} s_{i j} / 2\right), s_{i j}$ is the deviatoric stress tensor given by $s_{i j}=\sigma_{i j}-\delta_{i j} s_{k k} / 3$ and $\delta_{i j}$ is the Kronecker delta and $s_{k k}$ obeys the summation connection. The strain rate equation then becomes

$$
\frac{\mathrm{d} \varepsilon_{i j}}{\mathrm{~d} t}=\dot{\varepsilon}_{i j}=\frac{\mathrm{d} \Psi}{\mathrm{d} s_{i j}}=\frac{3}{2} G \sigma_{\mathrm{e}}^{n-1} s_{i j} t^{m},
$$

and the energy dissipation rate is given by

$$
\dot{D}=s_{i j} \dot{\varepsilon}_{i j}=\sigma_{\mathrm{e}} \dot{\varepsilon}_{\mathrm{e}}=G \sigma_{\mathrm{e}}^{n+1} t^{m} .
$$

(ii) Hyperbolic-sine law

Othman et al. (1993) have generalized equation (3.2) to multiaxial conditions using the scalar potential function

$$
\Gamma=\frac{A}{B(1-H)} \cosh \left(B \sigma_{\mathrm{e}}(1-H)\right) .
$$

The strain rate equation (3.2) then becomes

$$
\frac{\mathrm{d} \varepsilon_{i j}}{\mathrm{~d} t}=\dot{\varepsilon}_{i j}=\frac{d \Gamma}{d s_{i j}}=\frac{3 A}{2 \sigma_{\mathrm{e}}} s_{i j} \sinh \left(B \sigma_{\mathrm{e}}(1-H)\right),
$$

and the energy dissipation rate is given by

$$
\dot{D}=s_{i j} \dot{\varepsilon}_{i j}=A \sigma_{\mathrm{e}} \sinh \left(B \sigma_{\mathrm{e}}(1-H)\right) .
$$

\section{A thermodynamic framework for constitutive modelling}

\section{(a) General approach}

The first law of thermodynamics (Lemaitre \& Chaboche 1990) may be expressed as

$$
\rho \dot{e}=\sigma_{i j} \dot{\varepsilon}_{i j}+r+\operatorname{div} q,
$$

where $e$ is the specific internal energy, $\rho$ the density, $r$ is the rate of internal heat production, and $q$ is the heat flux per unit area.

The second law of thermodynamics expresses the irreversibility of entropy production (Lemaitre 1992) through the following inequality

$$
\rho \dot{S}+\operatorname{div} \frac{q}{T}-\frac{r}{T} \geq 0,
$$

where $S$ is the specific entropy and $\mathrm{T}$ is the absolute temperature. This equation may be transformed into the Clausius-Duhem inequality using the Helmholtz 
free energy $\psi=e-T S$, and the first law

$$
\Omega_{\text {int }}=\sigma_{i j} \dot{\varepsilon}_{i j}-\rho(\dot{\psi}+S \dot{T})-\frac{q_{i} T_{, i}}{T} \geq 0 .
$$

The Hemhotz free energy is a function of the state variables and may be written

$$
\dot{\psi}=\frac{\partial \psi}{\partial \varepsilon_{i j}^{\mathrm{e}}} \dot{\varepsilon}_{i j}^{\mathrm{e}}+\frac{\partial \psi}{\partial T} \dot{T}+\frac{\partial \psi}{\partial \gamma_{k}} \dot{\gamma}_{k}-\frac{\partial \psi}{\partial \omega_{l}} \dot{\omega}_{l},
$$

where $\gamma_{k}$ are $k$ hardening variables which may represent strain and dislocation mechanisms, and $\omega_{l}$ are $l$ softening or damage variables which may represent ageing, dislocation softening or cavity growth processes.

Inequality (4.3) when taken together with $\dot{\varepsilon}_{i j}=\dot{\varepsilon}_{i j}^{e}+\dot{\varepsilon}_{i j}^{p}$, where the superscripts $e$ and $p$ denote elastic and plastic strain rates respectively, can be written for isothermal conditions as

$$
\Omega_{\text {int }}=\sigma_{i j} \dot{\varepsilon}_{i j}^{p}-\rho \frac{\partial \psi}{\partial \gamma_{k}} \dot{\gamma}_{k}+\rho \frac{\partial \psi}{\partial \omega_{l}} \dot{\omega}_{l} \geq 0 .
$$

This equation for the intrinsic energy provides a means of interpretation of the energies, dissipated as heat, or stored in the material. The first term on the righthand side is the irreversible energy supplied during inelastic deformation; the second term is the energy stored by dislocation hardening mechanisms; and, the last term denotes the energy lost by heat and in the creation of new surfaces/phases by damage.

Equation (4.5) may be rewritten using the Legendre-Fenchel transformation (Chaboche 1999) to yield convex, positive potential functions of the type given by equations (3.3) and (3.6) which satisfy the normality rule and the second law, with and without damage. Hence the inelastic strain rate tensor may be written in the general form

$$
\dot{\varepsilon}_{i j}=\frac{\partial \Omega}{\partial \sigma_{i j}},
$$

so preserving the normality property provided that $\Omega$ is a differentiable, nonnegative, convex function containing the origin.

\section{(b) Deformation potential functions in the presence of damage}

In the presence of damage, the energy dissipation potentials can be rewritten by forming the product of the potential functions for the no-damage conditions, and the values of the relevant state variables. This has been justified by Leckie \& Hayhurst (1974) who have shown that, to a close first approximation, the damage state variables equally affect all components of the strain rate tensor.

Hence for the $n$-power creep law, equation (3.3), the potential function becomes

$$
\Psi=\frac{G}{(n+1)} \frac{\sigma_{e}^{n+1} t^{m}}{(1-\Phi)^{n}(1-\omega)^{n}},
$$

where $\omega$ is the creep constrained cavity growth state variable, and, $\Phi$ is the ageing state variable; and, for the hyperbolic-sine law (3.6), the potential function becomes

$$
\Gamma=\frac{A(1-\Phi)(1-\omega)}{B(1-H)} \cosh \left[\frac{B \sigma_{\mathrm{e}}(1-H)}{(1-\Phi)(1-\omega)}\right] .
$$


The state variable evolution equations and their stress-state sensitivities, given in later sections, cannot be derived from thermodynamic first principles. Instead, they have been derived from a knowledge of the physical mechanisms and empirical formulations based on extensive experimental data.

\section{Constitutive equations}

In this section, constitutive equations are presented for 590 and $620{ }^{\circ} \mathrm{C}$. At $590{ }^{\circ} \mathrm{C}$, the hyperbolic-sine stress sensitivity has been used in preference to the Norton power law form. This selection has been motivated entirely by the availability of calibrated equations sets; and by the results of studies carried out at $620^{\circ} \mathrm{C}$ by Hayhurst \& Perrin (1995) on welded pipes subjected to combined internal pressure and end load.

\section{(a) Material behaviour at $590^{\circ} \mathrm{C}$}

In low alloy ferritic steels, the Norton power law stress exponent, $n$, is assumed to be constant over limited ranges of stresses and temperatures. This issue has been addressed by Kowalewski et al. (1994) and Dyson \& Mclean (2000); who have shown that the hyperbolic-sine stress function is capable of describing the strain rate behaviour of these materials over a much wider range of stress. Since the material behaviour will be modelled over a wide range of stress, the latter formulation has been used for $590{ }^{\circ} \mathrm{C}$. The set of CDM-based constitutive equations models: hardening mechanism of creep, and two softening mechanisms, which include ageing and cavity initiation and growth. Hence the model incorporates three state variables. The first state variable, $H$, is used to represent the strain hardening effect attributed to primary creep. Initially, $H$ is zero and, as strain accumulates, it increases to a limiting value of $H^{*}$. The second state variable, $\Phi$, describes the coarsening of the carbide precipitates, and is defined from the physics of ageing to vary from zero to unity. The coarsening of the carbide precipitates or ageing leads to a progressive loss in the creep resistance of particle hardened alloys such as ferritic steels. The third state variable, $\omega$, represents inter-granular creep constrained cavitation damage and is chosen to vary from zero for the virgin state of metal to $\omega_{\mathrm{f}}$ at failure (Dyson \& Gibbons 1987). The multiaxial form of this set of constitutive equations is

$$
\begin{gathered}
\dot{\varepsilon}_{i j}=\frac{3 s_{i j}}{2 \sigma_{\mathrm{e}}} A \sinh \left[\frac{B \sigma_{\mathrm{e}}(1-H)}{(1-\Phi)(1-\omega)}\right], \\
\dot{H}=\left(h \dot{\varepsilon}_{\mathrm{e}} / \sigma_{\mathrm{e}}\right)\left[1-\frac{H}{H^{*}}\right], \\
\dot{\Phi}=\left(k_{\mathrm{c}} / 3\right)(1-\Phi)^{4}, \\
\dot{\omega}=C N \dot{\varepsilon}_{\mathrm{e}}\left(\sigma_{1} / \sigma_{\mathrm{e}}\right)^{\nu},
\end{gathered}
$$

where $\sigma_{1}$ is the maximum principal stress. $N=1$ when $\sigma_{1}>0$ and, $N=0$ when $\sigma_{1} \leq 0$. The material parameters: $A, B, C, h, H^{*}$ and $k_{\mathrm{c}}$ are constants to be 
Table 1. Material parameters for CDM-based constitutive equations set (5.1a-d) for each of the weldment materials of low alloy ferritic steel, $0.5 \mathrm{Cr} 0.5 \mathrm{Mo} 0.25 \mathrm{~V}$ welded with $2.25 \mathrm{Cr} 1 \mathrm{Mo}$ weld metal at $590^{\circ} \mathrm{C}$

\begin{tabular}{|c|c|c|c|c|}
\hline parameter & parent & weld & HAZ & Type IV \\
\hline $\mathrm{A}\left(\mathrm{h}^{-1}\right)$ & $2.1618 \times 10^{-9}$ & $2.5289 \times 10^{-10}$ & $2.1618 \times 10^{-9}$ & $6.8568 \times 10^{-8}$ \\
\hline $\mathrm{B}\left(\mathrm{MPa}^{-1}\right)$ & 0.20524 & 0.19106 & 0.20524 & 0.10414 \\
\hline $\mathrm{C}(-)$ & 1.8537 & 1.8537 & 1.8537 & 4.5550 \\
\hline $\mathrm{h}(\mathrm{MPa})$ & $2.4326 \times 10^{5}$ & $3.9070 \times 10^{4}$ & $2.4326 \times 10^{5}$ & $1.7441 \times 10^{4}$ \\
\hline $\mathrm{H}^{*}(-)$ & 0.5929 & 0.4625 & 0.5929 & 0.6500 \\
\hline $\mathrm{k}_{\mathrm{c}}\left(\mathrm{h}^{-1}\right)$ & $9.2273 \times 10^{-5}$ & $2.7289 \times 10^{-4}$ & $9.2273 \times 10^{-5}$ & $7.2572 \times 10^{-4}$ \\
\hline$v(-)$ & 2.8 & 2.8 & 2.8 & 2.8 \\
\hline$\omega_{\mathrm{f}}(-)$ & $1 / 3$ & $1 / 3$ & $1 / 3$ & $1 / 2$ \\
\hline
\end{tabular}

determined from the uniaxial creep behaviour. The parameter $\nu$ is the multiaxial stress sensitivity index.

Hayhurst \& Miller (1998) using the methods due to Perrin \& Hayhurst $(1996 a, b)$ have determined the material parameters for constitutive equations set $(5.1 a-d)$ at the temperature of $590{ }^{\circ} \mathrm{C}$ and these values are presented in table 1 . The approach followed is now briefly explained.

Material constants for the parent material have been determined by using numerical optimization methods to fit the model to experimental data. For this purpose, a functional has been defined and minimized, which is based on the error between the predicted and experimental creep data.

The experimental creep data for the Cast M1: $0.5 \mathrm{Cr} 0.5 \mathrm{Mo} 0.25 \mathrm{~V}$ ferritic steel used by Perrin \& Hayhurst (1996a) has been collected at constant load over a temperature range of $615-690^{\circ} \mathrm{C}$. These data have been supplemented by uniaxial creep test data reported by Flewitt et al. (1989). After determination of the associated activation energies for deformation and damage evolution, the material parameters for parent material at $590{ }^{\circ} \mathrm{C}$ have been obtained by extrapolation (Perrin \& Hayhurst 1996a; Hayhurst \& Miller 1998).

The normalized global creep property ratios (Perrin \& Hayhurst 1996b) have been used to determine the constitutive constants of the non-base weld and Type IV materials. Examination of the HAZs of butt-welds prepared for in-service operation shows that the microstructures vary from fine to coarse grain, with a predominance of the refined structure. This is recognized in the R5 assessment procedure (British Energy R5 2001) which makes provision for the definition of the ratio of coarse to fine grain microstructure. The purpose of this paper is to examine the transition between Type IV and FB cracking, and only one HAZ microstructure will be considered. The HAZ is assumed to have the same properties as the parent material, since real mixed HAZ microstructures are expected to behave more like fully refined than fully coarse structures. This is justified on two grounds: firstly, the work of Perrin \& Hayhurst (1999) used the assumption that the HAZ and parent materials have the same material properties to accurately predict the results of experiments on cross-weld testpieces; and secondly, the work of Hall \& Hayhurst (1991) accurately 

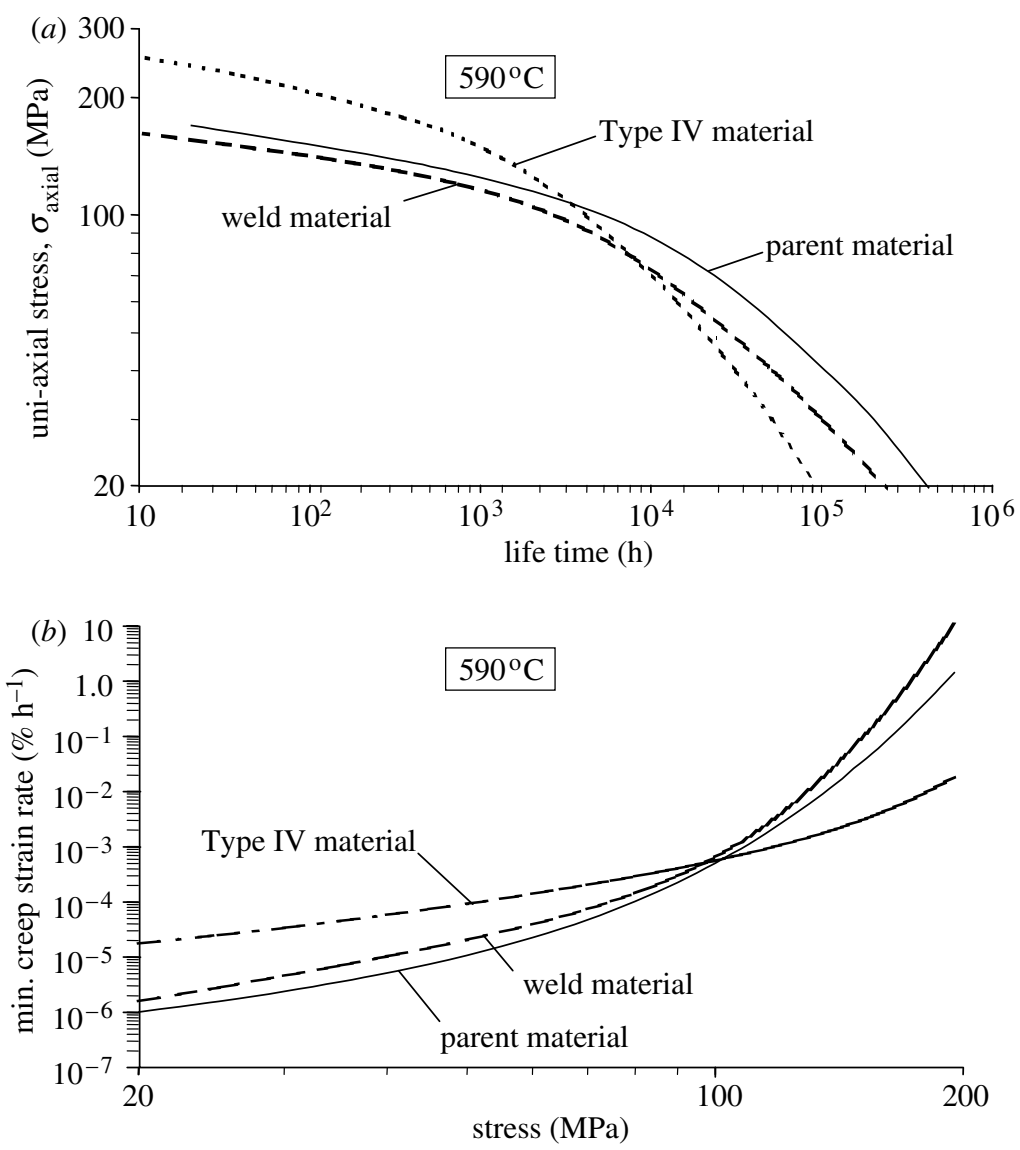

Figure 1. (a) Variation in uniaxial stress with lifetime for low alloy ferritic steel, $0.5 \mathrm{Cr} 0.5 \mathrm{Mo}$ $0.25 \mathrm{~V}$, parent, Type IV and weld material of $2.25 \mathrm{Cr} 1 \mathrm{Mo}$ at $590{ }^{\circ} \mathrm{C}$. (b) Variation in uniaxial minimum creep strain rate $\left(\% \mathrm{~h}^{-1}\right)$ with stress level for low alloy ferritic steel, $0.5 \mathrm{Cr} 0.5 \mathrm{Mo} 0.25 \mathrm{~V}$, parent, Type IV and weld material of $2.25 \mathrm{Cr} 1 \mathrm{Mo}$ at $590{ }^{\circ} \mathrm{C}$.

predicted the damage evolution and lifetime of a butt welded pipe from a knowledge of the uniaxial laboratory data and the multiaxial stress rupture criteria, the material behaviour for the HAZ and parent materials, assessed in terms of minimum creep rates and lifetimes, were within a factor of less than two.

Figure 1 shows the variation with uniaxial stress of creep rupture lifetimes and the minimum creep strain rates for the low alloy ferritic steel at $590{ }^{\circ} \mathrm{C}$ predicted using constitutive equations set $(5.1 a-d)$ together with the material data presented in table 1. It can be seen that for the stress level of below $80 \mathrm{MPa}$, the Type IV material shows the weakest behaviour both in terms of the damage evolution (cf. figure 1a) and minimum creep rate (cf. figure 1b).

Perrin \& Hayhurst (1996a) have determined a value for the multiaxial stress state index, $\nu=2.8$ (cf. equation $(5.1 d)$ ), using the lifetimes, the failure strains and the distributions of creep damage recorded from multiaxial creep rupture tests carried out by Flewitt et al. (1989) at $675{ }^{\circ} \mathrm{C}$. Since, the multiaxial stress state index, $\nu$, is not expected to vary significantly with temperature, it is assumed to have the same value, $\nu=2.8$, at $590{ }^{\circ} \mathrm{C}$. In the absence of any 
multiaxial creep rupture data for the weld materials at $590{ }^{\circ} \mathrm{C}$, the stress index, $\nu$, has been assigned the same value as for the parent material (Hayhurst \& Miller 1998). These assumptions have been justified using the experimental data recorded by Cane (1981) and Flewitt et al. (1989).

\section{(b) Material behaviour at $620^{\circ} \mathrm{C}$}

Coleman et al. (1985) have shown that Norton's power law adequately describes the creep behaviour of the low alloy ferritic steel. Since the conventional single damage state variable theory (Hayhurst et al. 1975; Hall \& Hayhurst 1991; Wang \& Hayhurst 1994a) is not capable of predicting softening due to carbide coarsening in low alloy ferritic steels, an additional state variable, $\Phi$, has been introduced by Perrin \& Hayhurst (1994a). They developed the following CDM-based constitutive equations set

$$
\begin{gathered}
\dot{\varepsilon}_{i j}=\frac{3}{2} \frac{G \sigma_{\mathrm{e}}^{n-1} s_{i j}}{(1-\Phi)^{n}(1-\omega)^{n}} t^{m}, \\
\dot{\Phi}=\left(k_{\mathrm{c}} / 3\right)(1-\Phi)^{4}, \\
\dot{\omega}=\frac{M\left(\alpha \sigma_{1}+(1-\alpha) \sigma_{\mathrm{e}}\right)^{\chi}}{(1-\Phi)^{\phi}(1-\omega)^{\phi}} t^{m},
\end{gathered}
$$

where $m, n, G, \chi, M, \phi$ and $k_{\mathrm{c}}$ are material constants and $\alpha$ is the multiaxial stress rupture criterion (Hayhurst 1972). The power law stress sensitivity form of the constitutive equations is an approximation to the hyperbolic-sine stress sensitivity equations set $(5.1 a-d)$. It can, therefore, only be expected to be valid over a restricted range of stress defined by the laboratory data, and is not appropriate for extrapolation over long times. However, to explain the creep behaviour over a wider stress range, two sets of material constants are used to describe the bilinear behaviour of the material. The values of the material constants for both the low and high stress regimes, which are summarized in table 2, have been obtained using the optimization and extrapolation methods developed by Perrin \& Hayhurst (1994b).

These methods are based on, and verified using the experimental data for the Cast M1 ferritic steel $0.5 \mathrm{Cr} 0.5 \mathrm{MO} 0.25 \mathrm{~V}$ reported earlier (Perrin \& Hayhurst 1994b). Although most of the data was collected at $635^{\circ} \mathrm{C}$, it covers a wide temperature range of $615-690^{\circ} \mathrm{C}$. Based on these data, Perrin \& Hayhurst (1994b) determined the material constants at $620^{\circ} \mathrm{C}$ using extrapolation techniques. The multiaxial stress rupture parameter, $\alpha$ (cf. equation (5.2c)), for the parent material and the HAZ were determined by Perrin \& Hayhurst (1994c) and Hall \& Hayhurst (1991), respectively. The multiaxial stress rupture parameter, $\alpha$, for the Type IV material has been assigned the same value of $\alpha$ as the parent material (Perrin 1995).

Figure 2 shows the creep rupture lifetime and the minimum creep strain rates for the low alloy ferritic steel at $620^{\circ} \mathrm{C}$ for different stress levels, obtained using CDM-based constitutive equations set $(5.2 a-c)$ together with the material data of table 2. It can be seen that for stresses below the level of $40 \mathrm{MPa}$, the Type IV material is the weakest. However, at this temperature, as may be observed from 
Table 2. Material parameters for CDM-based Constitutive equations set (5.2a-c) for each of the weldment materials of low alloy ferritic steel, $0.5 \mathrm{Cr} 0.5 \mathrm{Mo} 0.25 \mathrm{~V}$ welded with $2.25 \mathrm{Cr} 1 \mathrm{Mo}$ weld metal at $620^{\circ} \mathrm{C}$

(The units are stress in MPa, strain in percent and time in hours.)

\begin{tabular}{|c|c|c|c|c|c|c|c|c|}
\hline & \multicolumn{2}{|c|}{ parent material } & \multicolumn{2}{|c|}{ weld material } & \multicolumn{2}{|c|}{ HAZ material } & \multicolumn{2}{|c|}{ Type IV material } \\
\hline & $\sigma \leq \hat{\sigma}$ & $\sigma \geq \hat{\sigma}$ & $\sigma \leq \hat{\sigma}$ & $\sigma \geq \hat{\sigma}$ & $\sigma \leq \hat{\sigma}$ & $\sigma \geq \hat{\sigma}$ & $\sigma \leq \hat{\sigma}$ & $\sigma \geq \hat{\sigma}$ \\
\hline$\hat{\sigma}$ & 100 & 100 & 90 & 90 & 100 & 100 & 120 & 120 \\
\hline $\mathrm{m}$ & -0.2769 & -0.2881 & -0.3516 & -0.3515 & -0.2769 & -0.2881 & -0.2813 & -0.2852 \\
\hline $\mathrm{n}$ & 4.3523 & 7.4695 & 3.3994 & 6.1870 & 4.3523 & 7.4695 & 4.1774 & 6.4371 \\
\hline G & $\begin{array}{r}1.4718 \times \\
10^{-11}\end{array}$ & $\begin{array}{r}8.8830 \times \\
10^{-18}\end{array}$ & $\begin{array}{c}9.8332 \times \\
10^{-9}\end{array}$ & $\begin{array}{r}3.5085 \times \\
10^{-14}\end{array}$ & $\begin{array}{r}1.4718 \times \\
10^{-11}\end{array}$ & $\begin{array}{r}8.8830 \times \\
10^{-18}\end{array}$ & $\begin{array}{r}7.7666 \times \\
10^{-11}\end{array}$ & $\begin{array}{r}1.5651 \times \\
10^{-15}\end{array}$ \\
\hline$\chi$ & 4.8237 & 7.0673 & 3.2780 & 5.0312 & 4.8237 & 7.0673 & 4.3082 & 5.8702 \\
\hline M & $\begin{array}{r}1.5819 \times \\
10^{-13}\end{array}$ & $\begin{array}{r}2.5752 \times \\
10^{-18}\end{array}$ & $\begin{array}{c}2.2334 \times \\
10^{-9}\end{array}$ & $\begin{array}{r}4.5729 \times \\
10^{-13}\end{array}$ & $\begin{array}{r}1.5819 \times \\
10^{-13}\end{array}$ & $\begin{array}{r}2.5752 \times \\
10^{-18}\end{array}$ & $\begin{array}{r}3.4221 \times \\
10^{-12}\end{array}$ & $\begin{array}{r}1.1776 \times \\
10^{-15}\end{array}$ \\
\hline$\alpha$ & 0.15 & 0.15 & 0.4298 & 0.4298 & 0.15 & 0.15 & 0.15 & 0.15 \\
\hline$\phi$ & 4.0741 & 7.8750 & 2.8581 & 6.0354 & 4.0741 & 7.8750 & 3.9674 & 6.7131 \\
\hline $\mathrm{k}_{\mathrm{c}}$ & $\begin{array}{c}3.1659 \times \\
10^{-4}\end{array}$ & $\begin{array}{c}3.1659 \times \\
10^{-4}\end{array}$ & $\begin{array}{c}4.4413 \times \\
10^{-5}\end{array}$ & $\begin{array}{c}4.4413 \times \\
10^{-5}\end{array}$ & $\begin{array}{c}3.1659 \times \\
10^{-4}\end{array}$ & $\begin{array}{c}3.1659 \times \\
10^{-4}\end{array}$ & $\begin{array}{c}1.0225 \times \\
10^{-3}\end{array}$ & $\begin{array}{c}1.0225 \times \\
10^{-3}\end{array}$ \\
\hline
\end{tabular}

figure $2 b$, the weld material is the weakest in terms of minimum creep rate, regardless of the stress level.

Comparison of figures $1 a$ and $2 a$ indicates that, in respect of lifetimes, the behaviour at the two temperatures show similar relative strengths. However, figures $1 b$ and $2 b$ indicate different behaviour patterns. In both cases the parent is the most creep resistant whilst at $590{ }^{\circ} \mathrm{C}$ the Type IV material is the weakest; and, at $620^{\circ} \mathrm{C}$ the weld material is the weakest. This different pattern of behaviour is a consequence of the selected constitutive equations; and, the way in which the data has been extrapolated. It is the subject of a more detailed current investigation; however, for the purpose of this paper both equations will be used to test the sensitivity of the welded pipe behaviour to Type IV and to FB failure.

It is worth pointing out that at both 590 and $620^{\circ} \mathrm{C}$, the HAZ is in the fully refined form (Perrin 1995), and can be expected to have the same behaviour as the parent material. Consequently, the HAZ material has been assigned the same material parameters as the parent material.

In $\S 6$, the geometry of the butt-welded pipe is introduced, together with the internal pressure and end loading conditions.

\section{Pipe geometry and loading cases}

The geometry of the butt-welded steam pipe is shown in figure 3 together with the different material zones. The welded pipe is constructed from hot drawn $0.5 \mathrm{Cr} 0.5 \mathrm{Mo} 0.25 \mathrm{~V}$ parent material in the normalized and tempered condition using $2.25 \mathrm{Cr} 1 \mathrm{Mo}$ weld material. The welds are stress relieved, and are assumed to have zero residual stresses. The deformation and damage evolution of the pressurized pipe has been modelled using the FE CDM solver, DAMAGE XX (Hayhurst et al. 1984), and the constitutive equations sets $(5.1 a-d)$ and $(5.2 a-c)$. 

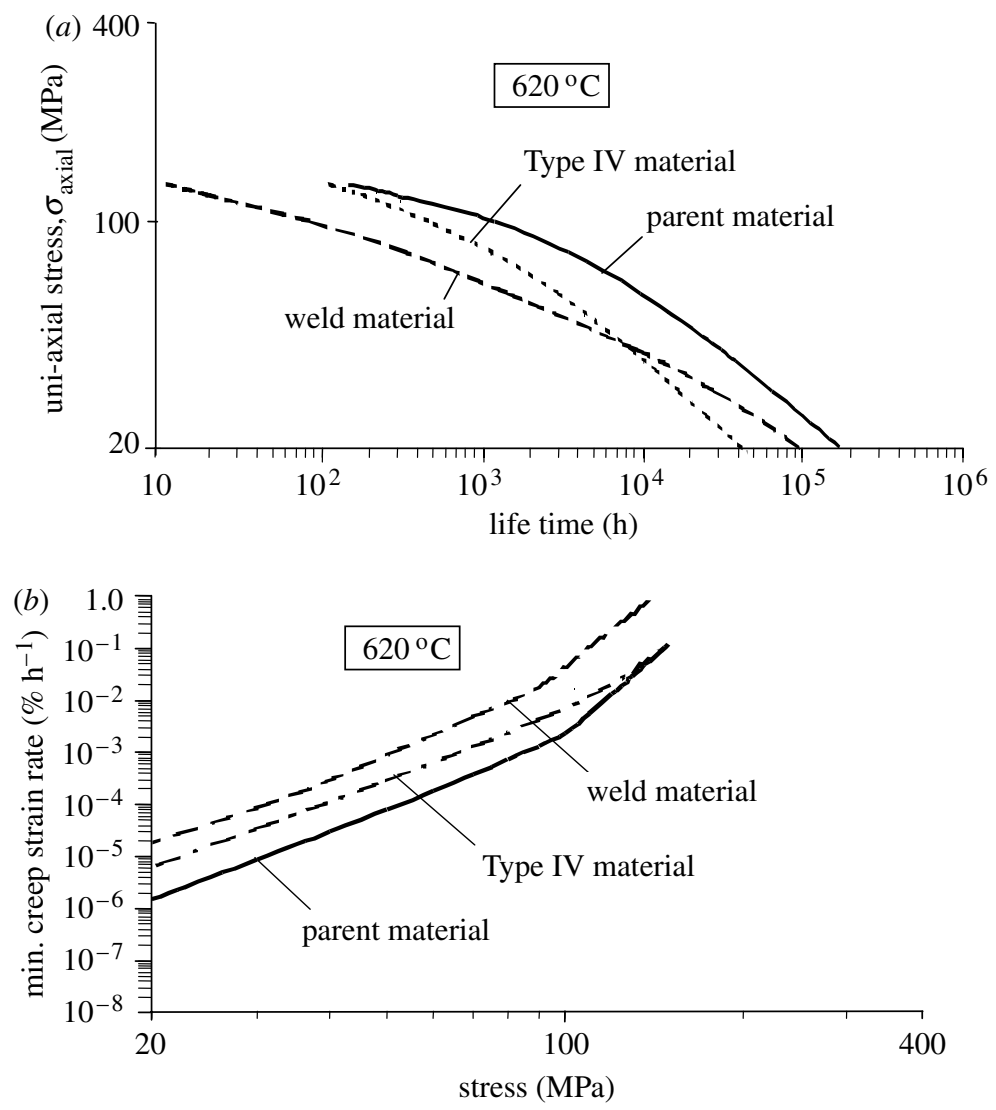

Figure 2. (a) Variation in uniaxial stress with lifetime for low alloy ferritic steel, $0.5 \mathrm{Cr} 0.5 \mathrm{Mo}$ $0.25 \mathrm{~V}$, parent, Type IV and weld material of $2.25 \mathrm{Cr} 1 \mathrm{Mo}$ at $620^{\circ} \mathrm{C}$. (b) Variation in uniaxial minimum creep strain rate $\left(\% \mathrm{~h}^{-1}\right)$ with stress level for low alloy ferritic steel, $0.5 \mathrm{Cr} 0.5 \mathrm{Mo} 0.25 \mathrm{~V}$, parent, Type IV and weld material of $2.25 \mathrm{Cr} 1 \mathrm{Mo}$ at $620^{\circ} \mathrm{C}$.

An axi-symmetric representation of the thick wall welded pipe is used, with the geometry given in figure 3. By virtue of the symmetry, only half of the welded pipe is modelled, and the FE discretization has been achieved using constant strain axi-symmetric triangular elements. The FE mesh has 4,392 degrees of freedom and 4,202 elements. The weld model is composed of four material regions: the parent, the weld, the Heat Affected and the Type IV material (cf. figure 3).

The boundary conditions for the model are specified in figure 3 . The total axial stress, $\sigma_{\text {axial }}$, which is applied as a boundary condition to the end of the pipe $/ \mathrm{mesh}$, is composed of two components given on the right hand side of the equation

$$
\sigma_{\text {axial }}=P_{\text {int }} /\left\{\left(D_{\text {out }} / D_{\text {in }}\right)^{2}-1\right\}+\sigma_{\text {end }},
$$

where $D_{\text {out }}$ and $D_{\text {in }}$ are external and internal diameters of the pipe, respectively. The first term on the right-hand side in equation (6.1) is due to the effect of the internal pressure acting on the end cap of the pipe, and the second term is due to an independently applied end stress, $\sigma_{\text {end }}$. 


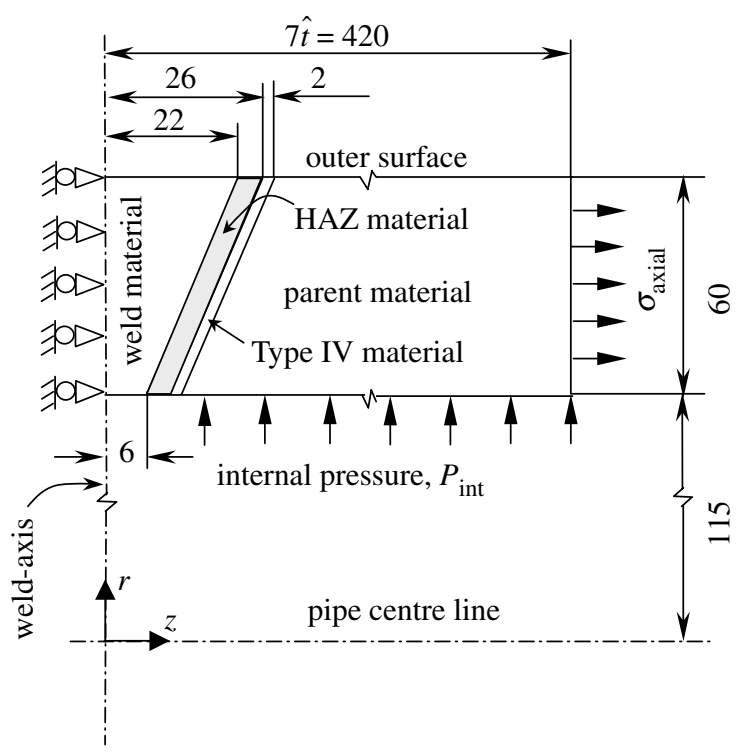

Figure 3. Dimensions and loading conditions for the low alloy ferritic steel steam pipe, $0.5 \mathrm{Cr} 0.5 \mathrm{Mo}$ $0.25 \mathrm{~V}$, welded with $2.25 \mathrm{Cr} 1 \mathrm{Mo}$. All dimensions are in $\mathrm{mm}$.

Four different loading conditions are considered:

(i) a uniaxially loaded pipe, $\sigma_{\text {axial }}$ with $\sigma_{\text {mdh }}=0$

(ii) mean diameter hoop stress, $\sigma_{\mathrm{mdh}}$, with $\sigma_{\text {axial }}=0$. The influence of the internal pressure on the end caps is neutralized by the application of a compressive end load, $\sigma_{\text {end }}$.

(iii) internal pressure stressing, $\sigma_{\mathrm{mdh}} / \sigma_{\text {axial }}=2$, where $\sigma_{\text {end }}=0$.

(iv) equi-biaxial tensile stressing, $\sigma_{\mathrm{mdh}} / \sigma_{\text {axial }}=1$. This is achieved by application of an additional tensile end stress, $\sigma_{\text {end }}$.

The loading conditions have been selected to represent a broad spectrum of design conditions; but, it is recognized that the equi-biaxial tension condition (iv) is the most severe, and is therefore the worst case considered in the design codes and assessment routes.

\section{Computational techniques}

The CDM-based FE solver, DAMAGE XX (Hayhurst et al. 1984), has been used to carry out creep analyses of the butt-welded pipe for the different loading conditions. Because of the features of the fine mesh used, small element-toelement variations in the field variables resulted in an increased stiffness of the governing equations. This, in turn, required increased solution times. In order to reduce the solution times, elemental values of the damage variable, $\omega$, were homogenized (appendix A). The homogenization of the damage values associated with each element, smoothes the damage gradients between adjacent elements. In this way, the stiffness of the differential equations is reduced and consequently, larger time-steps can be used for the time integration; run-times being typically 


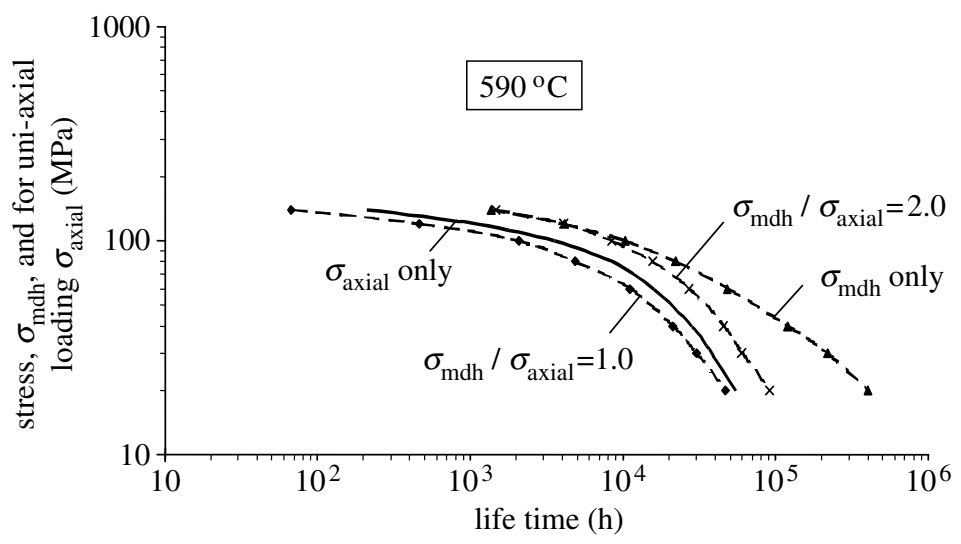

Figure 4. Variation of lifetime with stress level for a steam pipe, $0.5 \mathrm{Cr} 0.5 \mathrm{Mo} 0.25 \mathrm{~V}$, welded with $2.25 \mathrm{Cr} 1 \mathrm{Mo}$ at $590{ }^{\circ} \mathrm{C}$.

reduced by a factor of 12 . Application of the homogenization algorithm results in creep rupture times, which are a factor of $14 \%$ longer than the lifetimes obtained without use of the algorithm. The results obtained using the homogenization techniques for each of the loading cases presented have been corrected using at least three unhomogenized solutions spanning the range of the applied stresses. Although lifetimes for the two solution techniques are different, no perceptible differences were observed in the field variables except for damage being smoother and more continuous.

\section{Presentation of results}

Results are presented in this section; firstly, to show the effect of loading condition on the welded pipe lifetime; and, secondly to show how the uniaxial data for Type IV and weld materials influence the lifetimes of the welded pipes.

\section{(a) Effect of loading condition on pipe lifetime}

(i) Behaviour at $590^{\circ} \mathrm{C}$

Rupture times for the butt-welded pipe at $590{ }^{\circ} \mathrm{C}$ are presented in figure 4 . It can be seen that the loading case $\sigma_{\text {mdh }} / \sigma_{\text {axial }}=1$, gives the minimum lifetime when compared with the other loading conditions.

The next most severe loading case is that for axial loading $\left(\sigma_{\text {axial }}\right.$ only, with $\sigma_{\mathrm{mdh}}=0$ ) which has lifetimes of between 2-3 times longer than the $\sigma_{\text {mdh }} / \sigma_{\text {axial }}=1$ condition. Examination of figure $1 a$ shows that these lifetimes are significantly less than the lifetimes, for corresponding stress levels, of the uniaxial data. This is due to the multiaxial stresses generated by the materials mismatch in the weldment producing a weakening effect.

For the loading condition $\sigma_{\mathrm{mdh}} / \sigma_{\mathrm{axial}}=2$, due to internal pressure only, the lifetimes below $80 \mathrm{MPa}$ are similar to those given in figure $1 a$ for the Type IV material under uniaxial conditions. 


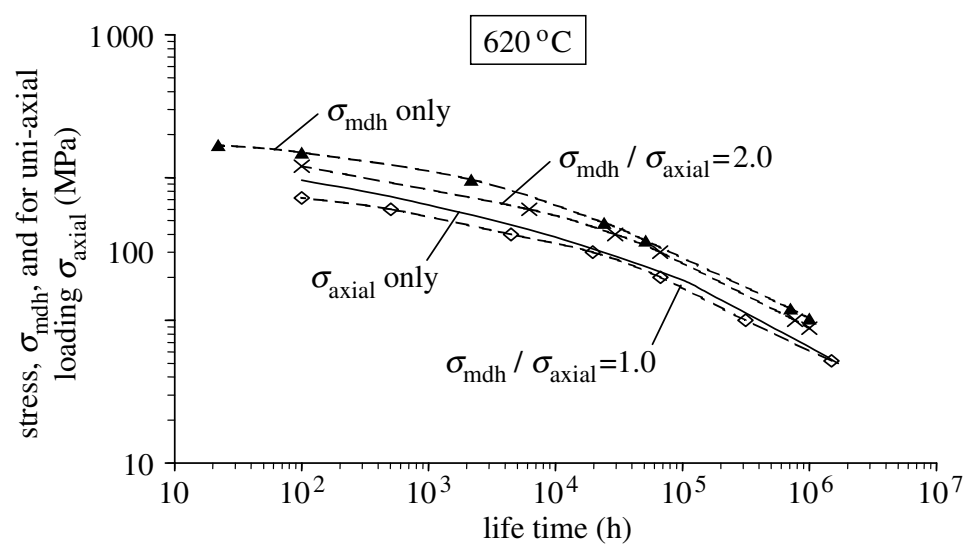

Figure 5. Variation of lifetime with stress level for a steam pipe, $0.5 \mathrm{Cr} 0.5 \mathrm{Mo} 0.25 \mathrm{~V}$, welded with $2.25 \mathrm{Cr} 1 \mathrm{Mo}$ at $620^{\circ} \mathrm{C}$.

For the $\sigma_{\text {mdh }}$ only loading case $\left(\sigma_{\text {axial }}=0\right)$, the pipe lifetimes are almost a factor of ten longer than those for the $\sigma_{\text {mdh }} / \sigma_{\text {axial }}=1.0$ loading case. For stresses below $80 \mathrm{MPa}$, the lifetimes are similar to those given in figure $1 a$ for the uniaxial parent material data.

\section{(ii) Behaviour at $620^{\circ} \mathrm{C}$}

Rupture times for the butt-welded steam pipe at $620^{\circ} \mathrm{C}$ are presented in figure 5 for different loading conditions. The same pattern of behaviour may be observed as that given for $590^{\circ} \mathrm{C}$ in figure 4 . The order of severity of loading cases being $\sigma_{\text {mdh }} / \sigma_{\text {axial }}=1,0,2, \infty$ with $\sigma_{\text {mdh }}$ only, i.e. $\sigma_{\text {mdh }} / \sigma_{\text {axial }} \rightarrow \infty$, having the longest lifetime. For stresses below $40 \mathrm{MPa}$, the maximum ratio of lifetimes with the lifetime in the $\sigma_{\mathrm{mdh}} / \sigma_{\text {axial }}=1$ case is approximately four; a figure which is low when compared to the factor of ten for $590{ }^{\circ} \mathrm{C}$.

Comparison of figure 5 with the corresponding uniaxial data of figure $2 a$ does not reveal the same conditions as for the temperature of $590{ }^{\circ} \mathrm{C}$ except that for stresses below $40 \mathrm{MPa}$, the lifetimes for the loading condition $\sigma_{\text {mdh }}$ only are approximately the same as the parent uniaxial values.

\section{(iii) Design}

The data presented in figures 4 and 5 for $590{ }^{\circ} \mathrm{C}$ and $620^{\circ} \mathrm{C}$, respectively, clearly show that the loading condition $\sigma_{\mathrm{mdh}} / \sigma_{\text {axial }}=1$ is the worst or least conservative condition. This confirms a procedure which is based on this fact and is well established in design codes. In the following discussions, attention will be focused on this loading condition, both for brevity and for its significance in design.

(b) The influence of uniaxial material properties of Type IV and weld materials on lifetimes of welded pipes

The effect of the uniaxial mechanical properties of the Type IV and weld materials on welded pipe lifetimes is now examined for both 590 and $620{ }^{\circ} \mathrm{C}$. 

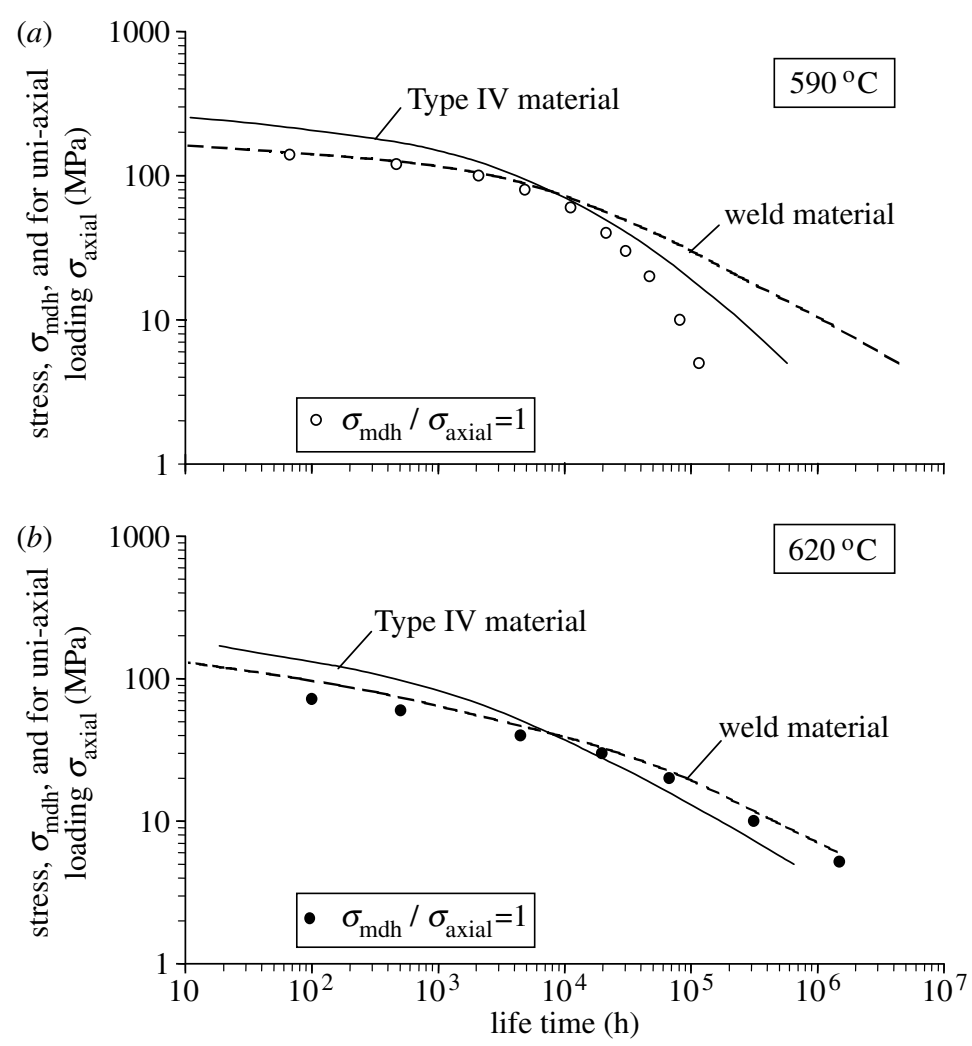

Figure 6. Comparison of the variation of lifetime of butt-welded pipes with the mean diameter hoop stress, $\sigma_{\mathrm{mdh}}$, for the loading condition $\sigma_{\mathrm{mdh}} / \sigma_{\text {axial }}=1$, with uniaxial data for the Type IV and weld materials. The solid and broken lines denote the uniaxial lifetime for the Type IV and weld materials, respectively. (a) Open circles denote the predicted pipe lifetimes at $590{ }^{\circ} \mathrm{C}$; and $(b)$ solid circles denote the predicted pipe lifetimes at $620^{\circ} \mathrm{C}$.

\section{(i) Behaviour at $590^{\circ} \mathrm{C}$}

Presented in figure $6 a$ is a comparison of uniaxial data for Type IV and weld materials with predicted pipe lifetimes for the loading condition $\sigma_{\text {mdh }} / \sigma_{\text {axial }}=1$. Comparison of the data leads to the conclusion that the weakening effect shown in the Type IV material data below the stress level of $80 \mathrm{MPa}$ causes a sharp bend in the lifetime- $\sigma_{\text {mdh }}$ curves. Above $\sigma_{\mathrm{mdh}}=80 \mathrm{MPa}$, the vessel lifetimes are approximately the same as those given by the welded material data. For these conditions the weld material has the minimum lifetime, given in figure $1 a$. Below this level, Type IV material is not only the weakest material for the initiation and growth of creep damage (cf. figure 1a), but also it has the largest minimum creep strain rate (cf. figure $1 b$ ). These two effects synergise and result in a shorter lifetime for the butt-welded pipe. For example in figure $6 a$ at $30 \mathrm{MPa}$ the Type IV material has a lifetime of $45000 \mathrm{~h}$, while at the same stress level the vessel lifetime is $30000 \mathrm{~h}$.

Hence, at lower stress levels, the source of weakening derives from the Type IV material having the shortest lifetimes and highest minimum creep rates relative to the weld and parent materials. 


\section{(ii) Behaviour at $620^{\circ} \mathrm{C}$}

Presented in figure $6 b$ is a comparison of uniaxial data for Type IV and weld materials with predicted lifetimes for the loading condition $\sigma_{\text {mdh }} / \sigma_{\text {axial }}=1$. Comparison of the data shows that the weakening effect in the Type IV data below the stress level of $40 \mathrm{MPa}$ causes a bend in the lifetime- $\sigma_{\mathrm{mdh}}$ curves at approximately $\sigma_{\mathrm{mdh}}=33 \mathrm{MPa}$. Above $\sigma_{\mathrm{mdh}}=33 \mathrm{MPa}$, the vessel lifetimes are significantly lower than for the weld material data; this is not only because the weld material has the shortest lifetimes, but, also because the minimum creep rates are higher (cf. figure 2b) than for any other material phase. This is analogous to the low stress behaviour at $590{ }^{\circ} \mathrm{C}$ where the Type IV material has the shortest lifetimes and largest minimum creep rate.

Below $\sigma_{\mathrm{mdh}}=33 \mathrm{MPa}$, the vessel lifetimes are higher than those given by the Type IV material data. However, the material with the highest minimum creep rates is the weld material, cf. figure $2 b$. The softer weld material clearly causes stresses to redistribute away from the Type IV region, so producing a stress state which causes the Type IV material to have increased lifetimes. Hence, a strengthening effect can be seen at low stress levels (figure 6b). For example, the creep lifetime for the butt-welded pipe at $10 \mathrm{MPa}$ with $\sigma_{\mathrm{mdh}} / \sigma_{\text {axial }}=1$ is $314475 \mathrm{~h}$ whereas the uniaxial rupture time for Type IV material at $10 \mathrm{MPa}$ is estimated to be $178550 \mathrm{~h}$.

\section{(iii) Design implications: materials selection}

It is clear that if either the Type IV or weld materials have the shortest lifetimes and highest minimum creep rates, then this is sufficient to produce stress-states and stress redistribution which results in a weakening of the welded pipe below that which might be expected from the corresponding material uniaxial data.

When selecting materials at the design stage, such property combinations should be avoided wherever possible.

\section{Interplay between fusion boundary and Type IV failure}

From figures 1-6, one would expect the failure zone to shift from the FB region at high stresses to the Type IV zone at low stresses. To understand the interplay between FB and Type IV failure, predicted damage distributions obtained from the FE CDM analyses of welded pipes are presented in figures 7 and 8 .

\section{(a) Behaviour at $620^{\circ} \mathrm{C}$}

Figure $7 a$ shows the damage, $\omega$, distribution close to failure for the pipe at $620{ }^{\circ} \mathrm{C}$ with $\sigma_{\mathrm{mdh}}=10 \mathrm{MPa}$, for $\sigma_{\mathrm{mdh}} / \sigma_{\text {axial }}=1$. Failure can clearly be seen to have taken place in the Type IV region. Initially the stress components are large at the inner bore of the pipe. Damage rates are therefore high in this region, consequently, stresses redistribute from the inner bore, radially outwards to the outer surface producing more uniform damage distribution across the section. In addition, the difference in the material properties causes more stress redistribution from the weld material into the HAZ and 


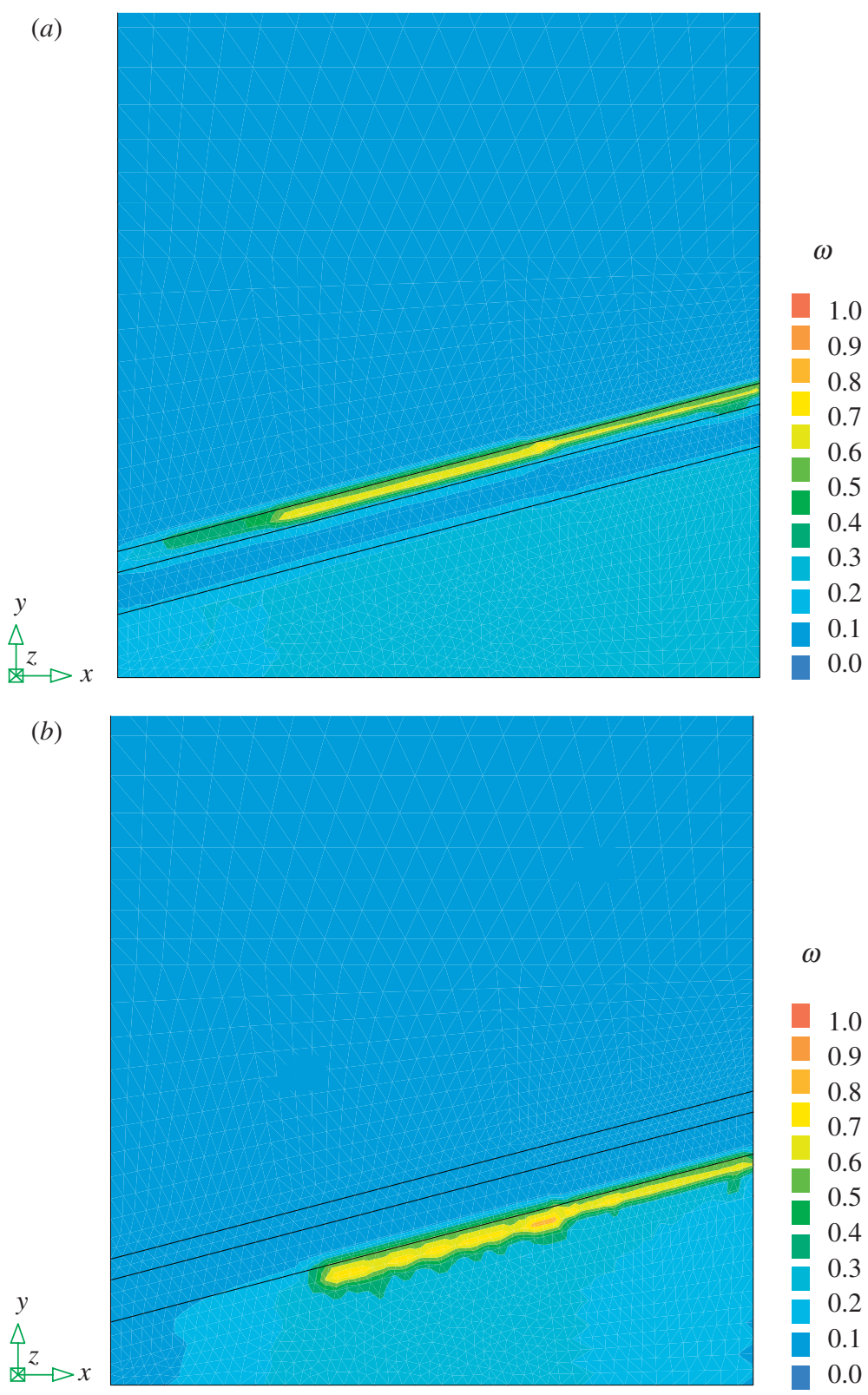

Figure 7. (a) Damage field, $\omega$, for a weldment at $620^{\circ} \mathrm{C}$ with $\sigma_{\mathrm{mdh}}=10 \mathrm{MPa}$, and $\sigma_{\mathrm{mdh}} / \sigma_{\text {axial }}=1$, close to failure at $314467 \mathrm{~h}$ showing Type IV failure. (b) Damage field, $\omega$, for a weldment at $620^{\circ} \mathrm{C}$ with $\sigma_{\mathrm{mdh}}=40 \mathrm{MPa}$ and $\sigma_{\mathrm{mdh}} / \sigma_{\text {axial }}=1$, close to failure at $4475 \mathrm{~h}$ showing fusion boundary failure.

Type IV regions. Hence, the peak stress shifts from the inner bore to a location near to the outer surface in the Type IV zone. This leads to the initiation and growth of damage along the Type IV region from the outer surface inwards.

The damage field, $\omega$, for the pipe at $620{ }^{\circ} \mathrm{C}$ is presented in figure $7 b$ with $\sigma_{\mathrm{mdh}}=40 \mathrm{MPa}$, for $\sigma_{\mathrm{mdh}} / \sigma_{\text {axial }}=1$, close to failure. Comparison of figure $7 a, b$ 

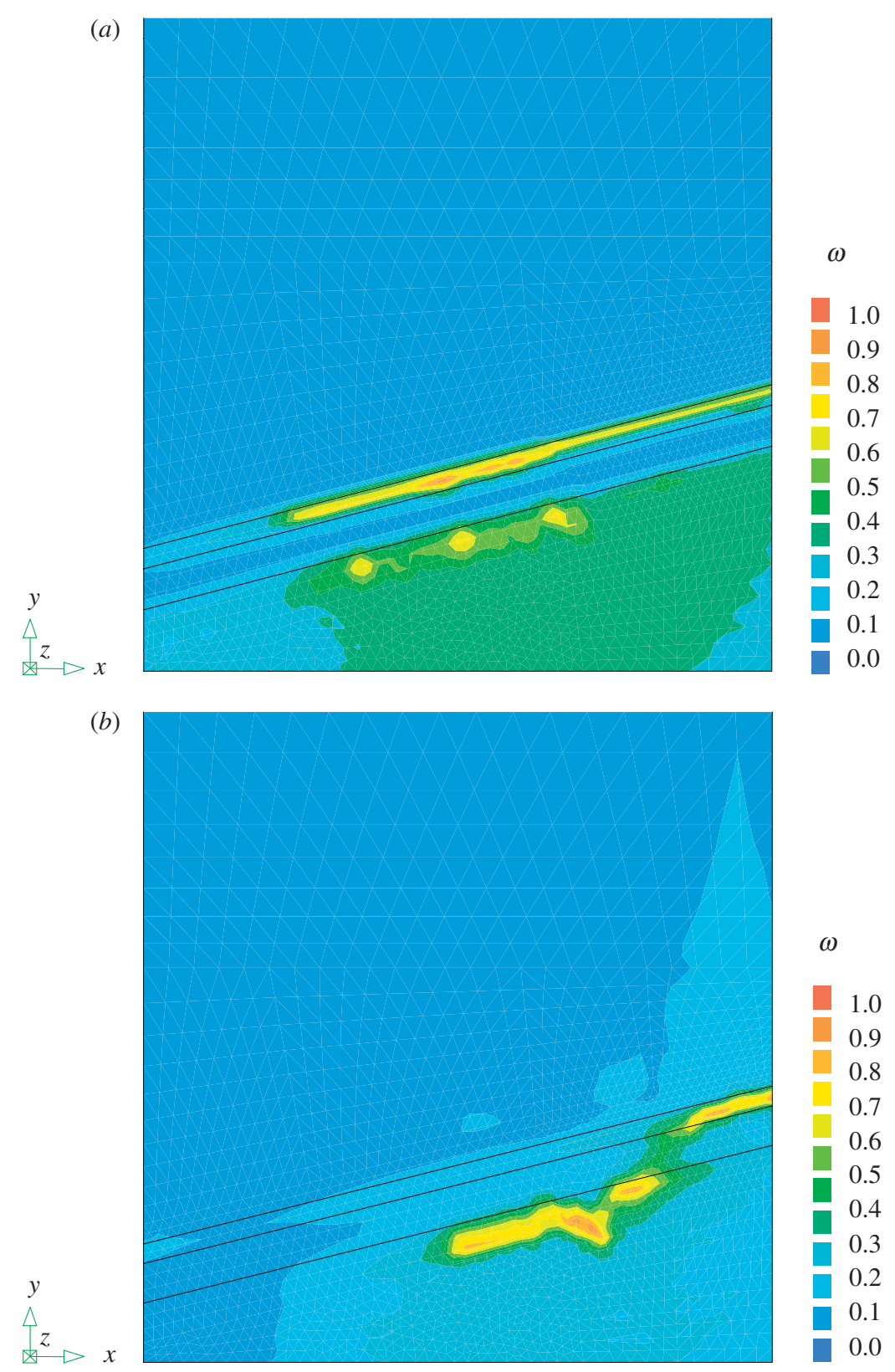

Figure 8. (a) Damage field, $\omega$, for a weldment at $620^{\circ} \mathrm{C}$ with $\sigma_{\mathrm{mdh}}=20 \mathrm{MPa}$ and $\sigma_{\mathrm{mdh}} / \sigma_{\text {axial }}=1$, close to failure at $67110 \mathrm{~h}$ showing mixed Type IV and fusion boundary failure. (b) Damage field, $\omega$, for a weldment at $590{ }^{\circ} \mathrm{C}$ with $\sigma_{\text {mdh }}=100 \mathrm{MPa}$ and $\sigma_{\text {mdh }} / \sigma_{\text {axial }}=1$, close to failure at $2375 \mathrm{~h}$ showing mixed Type IV and fusion boundary failure.

shows that failure shifts from the Type IV region at lower stresses to the FB zone at higher stresses. For the loading condition of $\sigma_{\mathrm{mdh}} / \sigma_{\text {axial }}=1$, the transition stress levels are found to be 30-35 MPa for the operating temperature of $620^{\circ} \mathrm{C}$. 

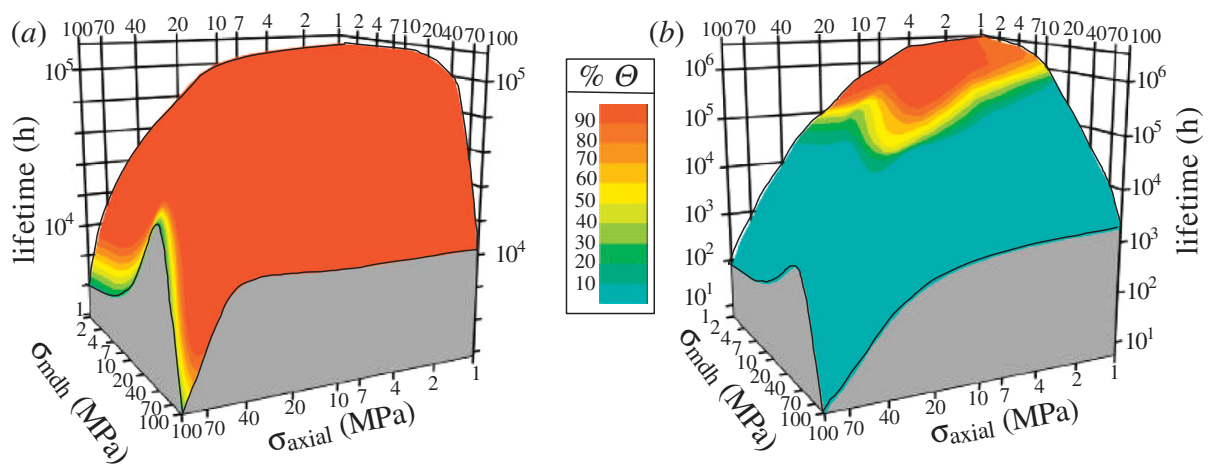

Figure 9. Variation of vessel lifetime with mean diameter hoop stress (smdh) and axial stress (saxial) for butt-welded ferritic steel pipes subjected to constant combined internal pressure and uniform end load at $(a) 590{ }^{\circ} \mathrm{C}$ and $(b) 620^{\circ} \mathrm{C}$. Colour contours represent the type of weld failure mode; $100 \%$ $\Theta$ denotes complete Type IV failure, and $0 \% \Theta$ denotes complete fusion boundary failure.

\section{(b) Behaviour at $590^{\circ} \mathrm{C}$}

The behaviour at $590{ }^{\circ} \mathrm{C}$ is similar to that at $620^{\circ} \mathrm{C}$ except that the transition stress level from FB failure to Type IV failure is increased to $80-100 \mathrm{MPa}$, cf. figure $6 a$.

\section{(c) Mixed mode fusion boundary and Type IV failure}

Figure 8 shows the mixed Type IV and fusion boundary failure for both operating temperatures. It may also be observed that additional tensile axial stress promotes the Type IV failure; figure $8 a$ shows dominant Type IV failure at $\sigma_{\text {mdh }}=20 \mathrm{MPa}$ while figure $8 b$ shows predominant fusion boundary failure at $\sigma_{\mathrm{mdh}}=100 \mathrm{MPa}$. It must be stressed that the kinematical determinacy of the pipe means that once advanced damage occurs at the outer surface of the pipe in the Type IV region, then failure takes place relatively quickly with only a small fraction of life spent in damage evolution in the fusion boundary region.

Figure 9 is presented to describe/characterize, in broad terms, the synergistic behaviour of the two failure modes with respect to the loading conditions and the operating temperature. This figure shows the variation of the creep rupture time with respect to the mean diameter hoop stress, $\sigma_{\text {mdh }}$, and the axial stress, $\sigma_{\text {axial, }}$, for a butt-welded pipe subjected to a constant combined uniform internal pressure and end load at the two different operating temperatures: 590 and $620^{\circ} \mathrm{C}$. In this figure the vertical axis represent the creep lifetime and the colour contours represent the type of weld failure mode. The value of $100 \%$ for $\Theta$ (red colour contours) denotes complete Type IV failure and, the value of $0 \%$ for $\Theta$ (dark green contours) denotes complete fusion boundary failure. Figure $9 a$ shows that at $590{ }^{\circ} \mathrm{C}$, below the stress level of $80 \mathrm{MPa}$, the failure is a complete Type IV mode; and, beyond this level up to $100 \mathrm{MPa}$, there is a mixed Type IV and fusion boundary failure (also see figures $7 a$ and $8 a$ ). These observations are consistent with the discussion presented in the previous section. The pronounced weakening effect of the Type IV material is the major reason for the dominance of this failure mode at $590{ }^{\circ} \mathrm{C}$. This weakening effect is a result of the susceptibility of the Type 
IV material to both damage evolution and creep deformation (cf. §8 and figure1). On the contrary, as can be seen in figure $9 b$, at $620^{\circ} \mathrm{C}$, complete Type IV failure is limited to stress levels below $15 \mathrm{MPa}$. Complete fusion boundary failure occurs at stresses above $35 \mathrm{MPa}$. Between these two stress levels, a mixed fusion boundary and Type IV failure can be observed (cf. figure $8 b$ ).

\section{Effect of multiaxial stress rupture criterion of Type IV material}

Although the mismatch in the uniaxial secondary creep rates of the constituent materials of the weldment has a major role in the relative behaviour of the weldments at $590{ }^{\circ} \mathrm{C}$ and $620{ }^{\circ} \mathrm{C}$ (cf. $\$ \S 8$ and 9), some part of the differences between the creep behaviour of the welded vessel at 590 and $620^{\circ} \mathrm{C}$ can be attributed to the different multiaxial stress rupture criteria employed for each material zone. At $590{ }^{\circ} \mathrm{C}$ for the hyperbolic-sine constitutive equations, where $\nu$ defines the multiaxial stress rupture criterion, each material zone has been assigned the same value of $\nu=2.8$, which corresponds to a value of $\alpha=0.4-0.5$, depending on the stress level (Perrin \& Hayhurst 1996b). At $620{ }^{\circ} \mathrm{C}$ for the power-law constitutive equations, where $\alpha$ defines the multiaxial stress rupture criterion, the value of $\alpha=0.15$ (bias towards the effective stress control for damage growth) has been taken for the parent, HAZ and Type IV materials, whereas the value of $\alpha=0.4298$ has been assigned for the weld material (balance between maximum principal stress and effective stress control for damage growth). The effect of different multiaxial stress rupture criteria for the Type IV material will now be investigated for the loading case $\sigma_{\text {mdh }} / \sigma_{\text {axial }}=1$.

It can be seen in figure $6 a$ that at $590{ }^{\circ} \mathrm{C}$, the weldment lifetimes fall below those of the uniaxial Type IV lifetimes, with the difference in lifetimes increasing as the stress reduces. Since the Type IV region with high creep deformation rate (cf. figure $1 b$ ) is highly constrained by the adjacent parent and HAZ zones, then the effective stress will be less than maximum principal stress i.e. $\sigma_{1} / \sigma_{\mathrm{e}}>1.0$ in this region. This fact reveals the important role of the $\sigma_{1} / \sigma_{\mathrm{e}}$ term particularly when it is raised to the power of $\nu=2.8$. As the applied load decreases, the Type IV region creeps proportionally faster than other material zones (cf. figure $1 b$ ) and this causes higher values of the ratio $\sigma_{1} / \sigma_{\mathrm{e}}$. Hence, the computed creep lifetimes diverge progressively from those for the Type IV uniaxial data as the stress level reduces. This effect is shown in figure 6 .

It can be seen in figure $6 b$ that at $620^{\circ} \mathrm{C}$ different behaviour is exhibited, partly because the weld metal creeps the most rapidly (although the Type IV material has the lowest uniaxial lifetime at low stress levels), and partly because the multiaxial rupture criteria for the weld metal is much more biased toward maximum principal stress $(\alpha=0.4298)$ than that for the Type IV region $(\alpha=0.15)$. Based on the above reasoning, if $\alpha$ for the Type IV material were increased to a similar value to that used at $590{ }^{\circ} \mathrm{C}$, then the relative lifetimes would be more like those for the $590{ }^{\circ} \mathrm{C}$, especially at low stress level where failure occurs in the Type IV zone. To see the effect of higher values of the multiaxial stress rupture criteria, $\alpha$, at $620^{\circ} \mathrm{C}$, its value was increased from 0.15 to 0.4298 (i.e. the same value as for the weld metal, which corresponds approximately to $\nu=2.8$ ). The creep lifetimes obtained using $\alpha=0.4298$ for the Type IV material are compared in table 3 with those for the previous solutions. It can be seen that as 
Table 3. Creep lifetime obtained using different values of the multiaxial stress rupture criteria, $\alpha$, for the Type IV material zone at $620^{\circ} \mathrm{C}$ for the loading case $\sigma_{m d h} / \sigma_{\text {axial }}=1$

(The $\alpha$ value for the weld, the HAZ and the parent material remained unchanged.)

\begin{tabular}{lrr}
\hline & \multicolumn{2}{c}{ lifetime $(\mathrm{h})$} \\
\cline { 2 - 3 }$\sigma_{\text {axial }}=\sigma_{\text {mdh }}(\mathrm{MPa})$ & $\alpha=0.4298$ & $\alpha=0.15$ \\
\hline 10 & 155989 & 314475 \\
20 & 35846 & 67110 \\
40 & 4486 & 4475 \\
60 & 504 & 505 \\
\hline
\end{tabular}

$\sigma_{\text {mdh }}$ decreases, with failure taking place in the Type IV region (cf. figure $9 b$ ), then the computed creep lifetimes for $\alpha=0.4298$ diverge progressively from the lifetimes obtained for lower value of $\alpha=0.15$; and, they fall below the uniaxial rupture times for the Type IV material (cf. figure $6 b$ ). Hence, this confirms the assertion made earlier.

These results highlight the importance of the multiaxial stress rupture criteria of all phases of the weldment; and, underscore the need for accurate experimental data.

\section{Failure at high internal pressures}

At high pressures for both 590 and $620{ }^{\circ} \mathrm{C}$, failure occurs in the parent material due to the large radial creep deformation in the weldment. For brevity, the associated mechanisms will now be discussed for pipes at $590{ }^{\circ} \mathrm{C}$ only. The failure mode is shown in figure 10 where, damage, $\omega$, and normalized effective creep strain profiles are presented for a butt-welded pipe at $590{ }^{\circ} \mathrm{C}$ with $\sigma_{\mathrm{mdh}}=140 \mathrm{MPa}$ for the loading condition of $\sigma_{\mathrm{mdh}} / \sigma_{\mathrm{axial}}=2$. The superimposed red profile denotes the deformed state of the pipe. It can be seen from figure $10 a$ that the damage is localized in the parent pipe. Figure $10 b$ shows the effective creep strain field with a concentration of strain in the weld region. The material data for $590{ }^{\circ} \mathrm{C}$ given in figure 1 , shows that for stresses greater than $100 \mathrm{MPa}$ the parent material has lower lifetimes and higher minimum creep rates than the Type IV material. This means that failure will either take place in the weld or parent material. The weld material zone deforms to take up a more favourable load carrying geometry, and stresses are redistributed from the weld to the parent pipe. Failure takes place in the parent pipe on a $45^{\circ}$ through-thickness surface where the maximum principal tension stress is high.

For vessels operated at $620^{\circ} \mathrm{C}$, the same mechanisms operate and the same explanations hold, except that the stress levels and pressures are different.

The failure mechanism reported for higher stress/pressures are mainly of academic interest, since design pressures for pipes used in plant are low enough for lifetimes to be in excess of $10^{5} \mathrm{~h}$, where failure takes place by Type IV failure. For this reason the parent pipe failure mode has been omitted from figure 9 . 
(a)

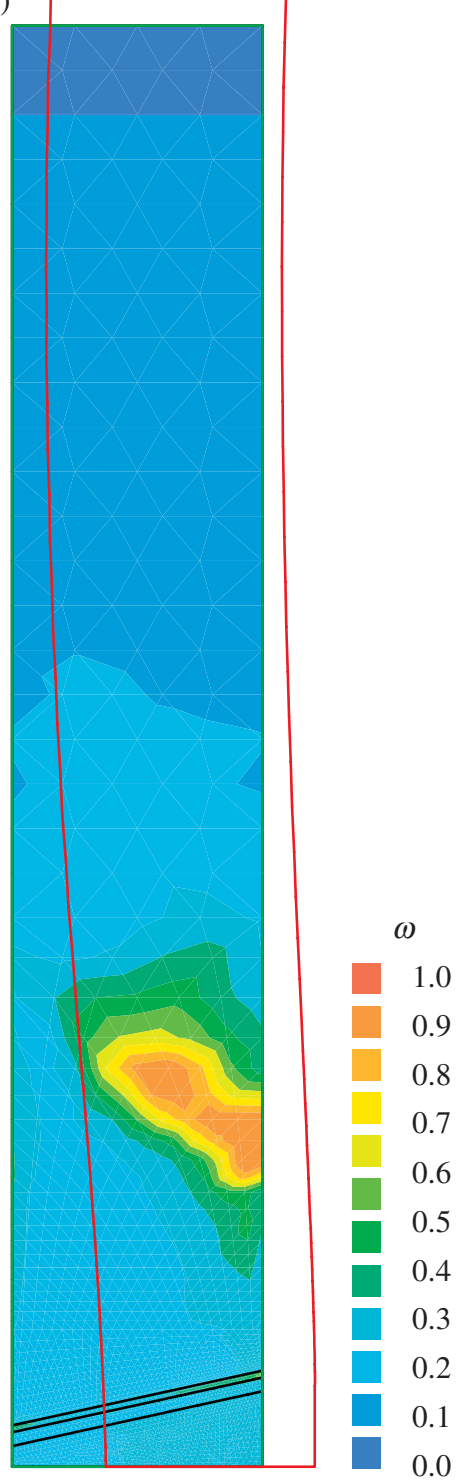

(b)

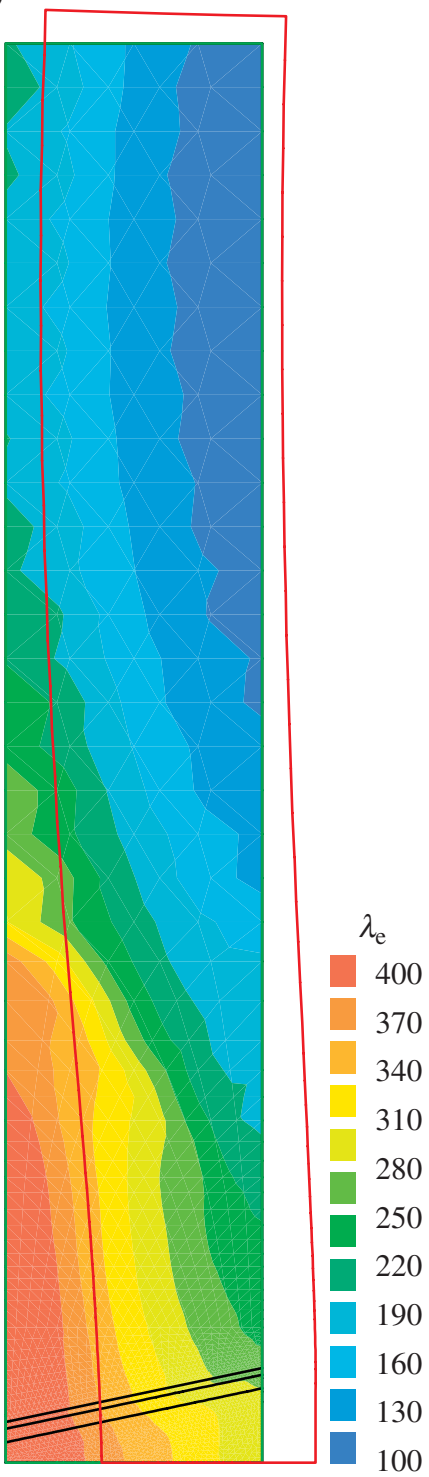

Figure 10. Damage field, $\omega,(a)$ and normalized effective creep strain, $\lambda_{\mathrm{e}}\left(=\varepsilon_{\mathrm{e}} / \varepsilon_{\mathrm{o}}\right),(b)$ for a pipe at $590{ }^{\circ} \mathrm{C}$, with $\sigma_{\mathrm{mdh}}=140 \mathrm{MPa}$, for loading condition $\sigma_{\mathrm{mdh}} / \sigma_{\text {axial }}=2$, close to failure at $1629 \mathrm{~h}$. The superimposed red profile denotes the deformed state of the pipe. Figure shows that the localized damage field $(a)$ and the effective creep strain field $(b)$ are compatible with this profile

\section{Approximate design formulae}

The objective of this section is to provide a set of simple design equations which provides a conservative approximation for the creep lifetime of the butt-welded pipe as a function of the internal pressure. This procedure will be presented in two parts, for the operating temperatures: 590 and $620^{\circ} \mathrm{C}$. 
Table 4. Coefficients of equation (12.1) used to describe the lifetime in hours as a function of mean diameter hoop stress in MPa for the welded pipe under the loading condition of $\sigma_{m d h} / \sigma_{\text {axial }}=1$

\begin{tabular}{lllll}
\hline $\mathrm{D}_{1}$ & $\mathrm{D}_{2}$ & $\mathrm{D}_{3}$ & $\mathrm{D}_{4}$ & $\mathrm{D}_{5}$ \\
\hline $2.01438 \times 10^{5}$ & $-5.48 \times 10^{4}$ & $5.97 \times 10^{2}$ & -0.7219 & $1.80 \times 10^{4}$ \\
\hline
\end{tabular}

(a) Butt-welded pipes operated at $590^{\circ} \mathrm{C}$

The hyperbolic-sine form of the CDM-based constitutive equations set $(5.1 a-d)$, which has been employed to describe the uniaxial creep behaviour of the low alloy ferritic steel at $590{ }^{\circ} \mathrm{C}$, cannot be integrated in closed form. However, the equation may be simplified by assuming $H=H^{*}$ and $K_{\mathrm{c}}=0$, then after integration (Appendix B) the following approximate relationship may be derived

$$
t_{\mathrm{f}}=D_{1}+D_{2} \ln \left(\sigma_{\mathrm{mdh}}\right)+D_{3} \sigma_{\mathrm{mdh}}+D_{4} \sigma_{\mathrm{mdh}}^{2}+\frac{D_{5}}{\sigma_{\mathrm{mdh}}^{2}},
$$

where $D_{i(i=1-5)}$ are constants which may be evaluated by fitting equation (12.1) to uniaxial experimental data. However, it is assumed that equation (12.1) may be used to describe the mean diameter hoop stress-lifetime behaviour of the welded pipe under the condition $\sigma_{\mathrm{mdh}} / \sigma_{\text {axial }}=1$, which gives the minimum lifetime in comparison with the other loading conditions (cf. figure 4). The implication is that this loading condition can be used to provide conservative lifetime predictions for all loading cases. In this way the approach will be appropriate for use in design codes. The results of the CDM FE analyses, cf. $\S \S 8$ and 9 , for the welded pipe with $\sigma_{\mathrm{mdh}} / \sigma_{\text {axial }}=1$ have been used to evaluate the constants $\mathrm{D}_{i(i=1-5)}$ in equation (12.1). These constants are given in table 4 . The open circles of figure 11 show that a satisfactory fit can be made using equation (12.1) over a wide range of stresses, which includes lifetimes of relevance in design of up to $8 \times 10^{4} \mathrm{~h}$.

Since there is a linear relationship between the mean diameter hoop stress $\sigma_{\mathrm{mdh}}\left(=P_{\mathrm{int}} D_{\mathrm{m}} / 2 \hat{t}\right)$ and the internal pressure, $P_{\text {int }}$, of the pipe, equation (12.1) may be rewritten as

$$
t_{\mathrm{f}}=G_{1}+G_{2} \ln \left(P_{\mathrm{int}}\right)+G_{3} P_{\mathrm{int}}+G_{4} P_{\mathrm{int}}^{2}+\frac{G_{5}}{P_{\mathrm{int}}^{2}},
$$

where the coefficients $G_{i(i=1,5)}$ are given in table 5 .

Examination of the open circles of figure 11 and the broken line of figure $6 a$ shows that for stresses $\sigma_{\mathrm{mdh}} \geq \sigma^{*}=80 \mathrm{MPa}$ the coefficients in equation (12.2) correspond to those for the weld material. For this domain, it may also be shown that a good approximation can be made by using equation (12.1) with $D_{5}=0$. In physical terms this corresponds to fusion boundary failure, cf. $\$ 8$ and 9 ; and, for higher values of $\sigma_{\mathrm{mdh}}$, to failure in the parent pipe which is controlled by creep deformation in the weld material, cf. $\$ 11$.

For stress $\sigma_{\mathrm{mdh}}<\sigma^{*}$, the description provided by equation (12.1) and shown in figure 11 may be simplified without loss of accuracy by setting $D_{4}=0$. As discussed in $\$ 8$ and 9 , the physical mechanism of failure is creep constrained cavity growth in the Type IV material region. Because of the stress-state effect created by the different stress level sensitivities of creep rates for the parent and Type IV materials, cf. figure $1 b$, this gives an increasingly weaker weldment as 


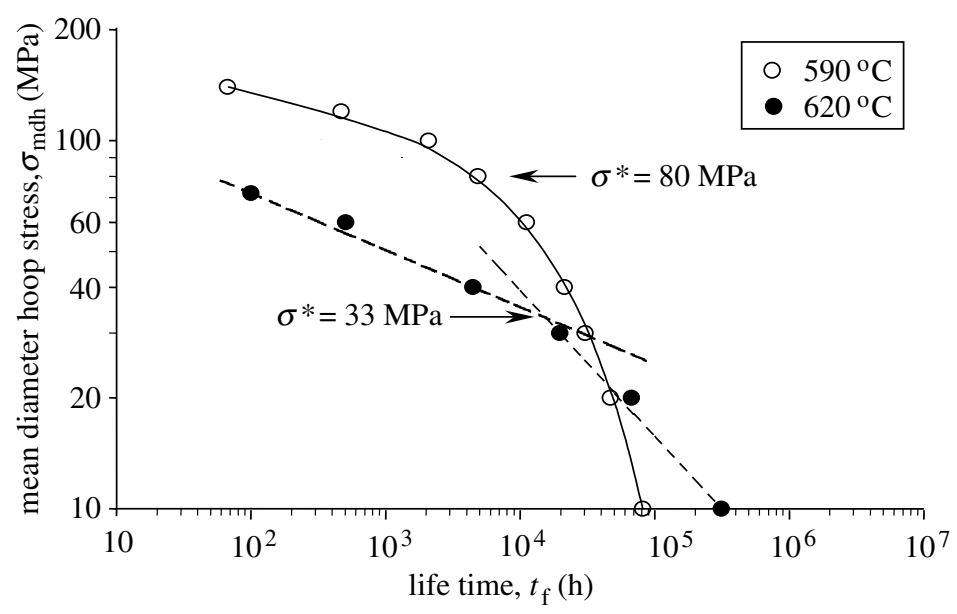

Figure 11. Comparison of the variation of the predicted lifetimes of butt-welded pipes, symbols, with the mean diameter hoop stress, $\sigma_{\mathrm{mdh}}$, for the loading condition $\sigma_{\mathrm{mdh}} / \sigma_{\text {axial }}=1$. The solid curve has been generated from the design equation (12.1). The broken lines represent data generated from the design equations $(12.3 a, b)$ above and below the break stress $\sigma^{*}$. The open and solid circles denote the CDM-based predicted results for 590 and $620^{\circ} \mathrm{C}$, respectively.

Table 5. Coefficients of equation (12.2) used to describe the lifetime in hours as a function of internal pressure in MPa for the welded pipe under the loading condition of $\sigma_{\text {mdh }} / \sigma_{\text {axial }}=1$

\begin{tabular}{lllll}
\hline $\mathrm{G}_{1}$ & $\mathrm{G}_{2}$ & $\mathrm{G}_{3}$ & $\mathrm{G}_{4}$ & $\mathrm{G}_{5}$ \\
\hline $1.53083 \times 10^{5}$ & $-5.48 \times 10^{4}$ & $1.443 \times 10^{3}$ & -4.216 & $3.082 \times 10^{3}$ \\
\hline
\end{tabular}

$\sigma_{\text {mdh }}$ decreases (cf. figure $6 a$ ). It is therefore not possible to relate the coefficients $D_{\mathrm{i}}$ in equation (12.1) to either parent or Type IV material rupture behaviour, given in figure $1 a$.

As a consequence, it is necessary to carry out the complete creep CDM analysis for the pipe weldment to determine lifetimes. Five data points are required to calibrate the coefficients $D_{1}-\mathrm{D}_{5}$, or, if $D_{4}$ is neglected for low stresses, then four data points are required.

The representation of the data presented in figure 11 for $590{ }^{\circ} \mathrm{C}$ can be achieved using equation (12.2), which can also be used for design and for extrapolation to longer lifetimes.

Since it may be possible to carry out the design of a welded pipe by doing less than three CDM analyses, it may be unnecessary to use equations (12.1) or (12.2). Instead, it will suffice to perform the calculations directly for the cases of interest. However, the power of using these equations is in interpolation and extrapolation involving many cases.

\section{(b) Butt-welded pipes operated at $620^{\circ} \mathrm{C}$}

The power law form of the CDM-based constitutive equations set $(5.2 a-c)$, which has been employed to describe the creep behaviour of the low alloy ferritic 
steel at $620^{\circ} \mathrm{C}$, implies that the associated design equations, which relate lifetime to internal pressure, should be of power law form. To enable one to explain the different failure modes, two sets of equations have been proposed for the stresses below and above the break stress level of $\sigma^{*}=33 \mathrm{MPa}$ (cf. $\S 8$ and 9 ). As was the case for $590{ }^{\circ} \mathrm{C}$, the data for the loading condition of $\sigma_{\mathrm{mdh}} / \sigma_{\text {axial }}=1$ are used as a worst case for the lifetime assessment. These results are used to establish the following set of approximate design relationships

$$
t_{\mathrm{f}}=1.0256 \times 10^{14} \sigma_{\mathrm{mdh}}^{-6.4683} ; \text { for } \sigma_{\mathrm{mdh}} \geq \sigma^{*},
$$

and

$$
t_{\mathrm{f}}=1.0472 \times 10^{8} \sigma_{\mathrm{mdh}}^{-2.5225} ; \text { for } \sigma_{\mathrm{mdh}} \geq \sigma^{*},
$$

or

$$
t_{\mathrm{f}}=3.4058 \times 10^{11} P_{\mathrm{mdh}}^{-6.4683} ; \text { for } P_{\mathrm{int}} \geq 13.7 \mathrm{Mpa},
$$

and

$$
t_{\mathrm{f}}=1.1308 \times 10^{7} P_{\text {int }}^{-2.5225} ; \text { for } P_{\text {int }} \geq 13.7 \mathrm{MPa},
$$

where $\sigma^{*}=33 \mathrm{MPa}$. Figure 11 shows that a satisfactory fit can be made over a wide range of stresses, which includes lifetimes of relevance in design of up to $3 \times 10^{5} \mathrm{~h}$.

\section{(c) Extrapolation of data}

Two different constitutive equations have been used. Equations sets $(5.1 a-d)$ and $(5.2 a-c)$ which incorporate hyperbolic-sine and power law stress sensitivities, respectively. These are quite distinct equations, derived for the same material at different temperatures; and, one would not expect to be able to extrapolate from one equations set at $590{ }^{\circ} \mathrm{C}$ to the other at $620^{\circ} \mathrm{C}$ over a wide range of stress. In particular, to extrapolate to long lifetimes in excess of $3 \times 10^{5} \mathrm{~h}$ equations sets $(5.1 a-d)$ and $(5.2 a-c)$ will give different lifetimes, with the hyperbolic-sine relationship $(5.1 a-d)$ giving shorter lifetimes. Equations set $(5.1 a-d)$ is regarded as being more reliable, since it is based on the physics of the governing processes of ageing and creep constrained cavity growth with the correct stress-state sensitivities. The power law model is merely an approximation to the hyperbolicsine law, valid over a restricted stress range. Therefore, care should be taken if extrapolation is attempted between the two temperatures at low stresses.

\section{(d) Use of design equations}

Given that relations exist of the type given by equations $12.1-12.4 b$, then they may be used to determine the lifetimes of butt-welded pipes subjected to arbitrary loading conditions; and they will yield conservative results. It may, in addition, be necessary to employ a safety factor, particularly for the condition $\sigma_{\mathrm{mdh}} / \sigma_{\text {axial }}=1$. Use of the equations embodies a knowledge of the failure mode, the high stress equations relate to fusion boundary and the low stress equations to Type IV failure, for the condition $\sigma_{\mathrm{mdh}} / \sigma_{\text {axial }}=1$. For other loading conditions, it is necessary to use figure 9 to determine the precise failure mode. 
When relations of the type $12.1-12.4 b$ do not exist, then it is necessary to perform CDM analyses using DAMAGE XX. To generate the design equations, an alternative to carrying out many computer solutions would be to estimate the break stress from fusion boundary to Type IV failures from the uniaxial data; perform two analyses for $\sigma_{\mathrm{mdh}} / \sigma_{\text {axial }}=1$; one with the stress above the break stress, $\sigma^{*}$; and another with the stress below $\sigma^{*}$; followed by a third analysis at high stress, and by a fourth analysis at very low stress. In this way, approximate design equations can be obtained with reduced computational effort.

If enough data is not available to support the CDM approach, other approximate methods can be used (Perrin et al. 2000) for the analysis of buttwelds. Although solutions can be obtained by using these methods with less computational effort, they do not provide detailed information prior to the formation of a macro-crack. Hence, the most reliable approach is to use the CDM analysis technique.

\section{British Energy R5 assessment procedure}

For the purpose of weld assessments in Cr Mo V pipe work components, the R5 assessment procedure (British Energy R5 2001) Volume 7 considers four distinct weldment zones or constituents: (i) $\mathrm{Cr}$ Mo V parent material (unaffected by welding), (ii) parent Type IV zone, (iii) parent HAZ and (iv) $2 \mathrm{Cr}$ Mo weld metal. In the present case, the properties of the HAZ are assumed to be the same as the parent material, i.e. it is assumed that a refined grain structure is present in the HAZ. Consequently only three zones require consideration.

To accomplish a weld assessment using the R5 procedure (British Energy R5 2001), the following information is required for these zones: (i) material creep rupture properties, (ii) stress redistribution factor, $k$, which ensure that the long term compatibility of circumferential creep strains is maintained.

For geometries and loadings considered here, where the creep reference stress is dominated by the hoop stress, it is necessary to modify the reference stress (Perrin et al. 2000) by a factor $\mathrm{k}$ to ensure creep strain compatibility. This factor accounts for the stress redistribution (e.g. off-loading from weaker weld constituents to the stronger ones) across the weldment. The values of the $\mathrm{k}$ factor for hoop and axial stress dominated conditions at $565{ }^{\circ} \mathrm{C}$ for all material constituents is taken as unity, with the exception of the case for the hoop stress in the weld constituent for which the $\mathrm{k}$ factor is taken as 0.7 .

Reference to figures $1 b$ and $2 b$ show that the weld metal creeps faster than the parent material at both 590 and $620^{\circ} \mathrm{C}$. This is in line with the R5 assessment procedure which indicates that at $565{ }^{\circ} \mathrm{C}$ the weld metal creeps faster than the parent material hence the $\mathrm{k}$ factor is 0.7 .

The above observations on creep deformation may be relevant in providing an explanation of the creep rupture response of the pipes, which are given in figure $6 a, b$. At $620^{\circ} \mathrm{C}$ (cf. figure $6 b$ ), the rupture times for the pipes are broadly in line with the advice given in the R5 assessment procedure; failure times follow the lower of the rupture line for the weld metal and the Type IV region. Note that in the R5 assessment procedure, for $\sigma_{\mathrm{mdh}} / \sigma_{\text {axial }}=1$, the value of the axial stress in the weld metal determines the weldment lifetime. 
At $590{ }^{\circ} \mathrm{C}$, cf. figure $6 a$, the rupture times for the pipes are hard to explain by using the design assessment route R5 in that they fall well short of the rupture line for the Type IV region. There are two possible reasons for this: (i) the stresses in the Type IV region are much higher due to the lower creep rates in the parent and weld metals; this seems plausible; and (ii) the multiaxial stress rupture criterion for the Type IV material at $590{ }^{\circ} \mathrm{C}$ has been taken as $\nu=2.8$ (approximately equivalent to $\alpha=0.43$ ) whereas in reality it is probably closer to the value of $\alpha=0.15$ selected for the temperature of $620^{\circ} \mathrm{C}$ (cf. $\S 8$ ). The studies reported in $\$ 10$ clearly highlight the importance of an accurate knowledge of the multiaxial stress rupture criterion.

\section{Conclusions}

A review has been presented of the constitutive equations used to model creep deformation and rupture of low alloy ferritic steels in the temperature range $590-620^{\circ} \mathrm{C}$. A thermodynamic framework has been provided for the deformation potential theory used in these equations.

CDM analyses have been performed using the FE CDM-based solver, DAMAGE XX, to predict the high-temperature creep behaviour of low alloy ferritic steel butt-welded steam pipes.

The analyses show that the failure mode is strongly dependent upon the operating temperature, loading condition and the stress level. At high stress/pressure failure takes place in the fusion boundary; and, at low stress/pressure failure occurs in the Type IV region.

A Failure mechanisms diagram has been generated to enable the determination of the mechanism as a function of stress state, stress level and temperature.

The reason for the switch in failure mechanism at both 590 and $620{ }^{\circ} \mathrm{C}$ from fusion boundary failure at high stress to Type IV failure at low stress can be traced to the log stress-log lifetime and log stress-log minimum creep strain rate curves for the uniaxial data for all the material phases of the weldment: Parent, HAZ, Type IV and weld materials. It is the change with stress level of the relative strengths that determines the overall behaviour of butt-welds. When a material phase has both the shortest lifetimes and largest minimum creep rates relative to the other material phases of the weldment then failure occurs in that phase producing a weakening relative to the uniaxial data for corresponding stress levels.

The importance is stressed of an accurate knowledge of the multiaxial stress rupture criteria of the constituent phases of the weldment.

The constitutive equations with hyperbolic sine stress level sensitivity, used for $590{ }^{\circ} \mathrm{C}$, are appropriate for extrapolation over a wide range of stresses, since they are based on the physics of the governing processes. But, the power law equivalent set of equations, used for $620^{\circ} \mathrm{C}$, is an approximation over a restricted stress range, and care should therefore be exercised in extrapolating between the two equations sets for different temperatures, over a wide range of stresses.

Design equations are proposed which are based on the critical equi-biaxial loading condition: $\sigma_{\mathrm{mdh}} / \sigma_{\text {axial }}=1$; their use provides conservative designs. Their 
formulation and proposed use is based on the physical understanding provided by the detailed results of the CDM analyses.

The research has been carried out as part of an EPSRC-ERCOS programme under grant GR/M44941; and funding has been provided by British Energy, Barnwood. Interactions with Professor B. F. Dyson, Dr D. W. Dean, Dr D. A. Miller and Dr I. W. Goodall are gratefully acknowledged. The help of Dr I. J. Perrin in the early planning stages of the research is gratefully appreciated. The authors gratefully acknowledge the work of Mr. Teo Hoon Hong in producing figure 9 of the paper. This paper was finalized while D. R. Hayhurst was on sabbatical leave at the University of California at Santa Barbara, USA; he acknowledges the financial support provided, through a Global Research Award, of the Royal Academy of Engineering of the United Kingdom.

\section{Appendix A. Homogenization of the damage state variable}

To reduce the run-times for the DAMAGE XX, elemental values for the damage variation, $\omega^{(e)}$, have been homogenized. In this way, the damage gradient between adjacent elements is reduced. For this purpose, an average nodal damage value, $\bar{\omega}_{i}$, for each node (for example node $i$ ) is determined by

$$
\bar{\omega}_{i}=\frac{1}{N} \sum_{q=1}^{N} \omega^{(q)},
$$

where $\omega^{(q)}$ is the elemental damage value for the $q$ th constant stress, strain and damage element, and $\mathrm{N}$ is the total number of elements which are connected to node $i$. Then an average elemental value, $\bar{\omega}^{(q)}$, is obtained for each element by using three average nodal values associated with that particular element

$$
\bar{\omega}^{(q)}=\frac{1}{3}\left(\bar{\omega}_{i}+\bar{\omega}_{j}+\bar{\omega}_{k}\right),
$$

where $\bar{\omega}_{i}, \bar{\omega}_{j}$ and $\bar{\omega}_{k}$ are the average nodal damage values for the three nodes: $i, j$ and $k$ of the element $q$. The algorithm is executed each iteration, and the homogenized values of elemental damage values are used to compute the current strain rates. In all other respects the algorithm remains unchanged.

\section{Appendix B. Approximate integration of the constitutive equations at $590{ }^{\circ} \mathrm{C}$}

To integrate the constitutive equations set $(5.1 a-d)$ in closed form, the following assumptions have been made. Firstly, the primary creep hardening state variable, $H$, is assumed to take its steady state value $H^{*}$; and, secondly, the role of the damage state variable, $\Phi$, which represents the coarsening of the carbide precipitates, or ageing, is neglected by assuming $k_{\mathrm{c}}=0$. Therefore, the uniaxial form of the constitutive equations set $(5.1 a-d)$ has been integrated neglecting the coupling with state variables $H$ and $\Phi$. The resultant equation will be approximate, since the coupling between variables can be significant; however, this equation will be used only to identify a suitable functional form required to describe lifetimes. While this assumption is not strictly valid, since ageing takes place over long periods at low stresses, the creep constrained cavity growth 
parameter, $\omega$, dominates; hence, the assumptions permit a good approximation to true lifetimes to be obtained. Therefore, the constitutive equations set $(5.1 a-d)$ can be rewritten in uniaxial form as

$$
\dot{\omega}=A C N \sinh \left[\frac{B \sigma(1-H *)}{(1-\omega)}\right] .
$$

Integration of the above equation between initial and final values of $\omega=0$ at $t=0$ and $\omega=\omega_{\mathrm{f}}$ at $t=t_{\mathrm{f}}$, respectively, will give the creep rupture time as a function of stress level, $\sigma$. To execute the integration, the transformation $u=Q /(1-\omega)$ is introduced where $Q\left(=B \sigma\left(1-H^{*}\right)\right)$ is a function of stress. Hence, lifetime, $t_{\mathrm{f}}$, will be

$$
t_{\mathrm{f}}=\frac{Q}{R} \int_{Q}^{u_{\mathrm{f}}} \frac{\mathrm{d} u}{u^{2} \sinh (u)}
$$

where $R(=A C N)$ is a material constant. The above integral can be rewritten as

$$
t_{\mathrm{f}}=\frac{Q}{R}\left[\frac{-1}{6} \ln (u)-\frac{1}{2 u^{2}}+\sum_{k=2}^{\infty} \frac{2-2^{2 k}}{(2 k) !(2 k-2)} \boldsymbol{B}_{2 k} u^{2 k-2}\right]_{Q}^{u_{\mathrm{f}}},
$$

where $\left.\boldsymbol{B}_{2 k}\left(=\sum_{i=0}^{2 k} C_{2 k}^{i} \boldsymbol{B}_{i}\right)\right)$ are the Bernoulli numbers. The truncation of the above series after the third term gives

$$
t_{\mathrm{f}}=\frac{Q}{R}\left[\frac{-1}{6} \ln (u)-\frac{1}{2 u^{2}}+\frac{7}{720} u^{2}\right]_{Q}^{u_{\mathrm{f}}}+\xi,
$$

where $\xi$ is the truncation error. For convenience, equation (B 4) can be rewritten as a function of stress

$$
t_{\mathrm{f}}=A_{1}+A_{2} \ln (\sigma)+A_{3} \sigma^{2}+\frac{A_{4}}{u^{2}}+\xi
$$

where $A_{i(i=1-4)}$ are constants. Evaluation of the error term, $\boldsymbol{\xi}$, can be achieved by calibration against the experimental data. It was observed that this could be best achieved by describing $\xi$ using a term which is linear in stress, this results in the accurate determination of creep lifetimes. Hence, the following form of the equation is used

$$
t_{\mathrm{f}}=D_{1}+D_{2} \ln (\sigma)+D_{3} \sigma+D_{4} \sigma^{2}+\frac{D_{5}}{\sigma^{2}},
$$

where $D_{i(i=1-5)}$ are constants.

\section{References}

Andrade, E.N.da.C. 1910 The viscous flow in metals and allied phenomena. Proc. R. Soc. A 84, 1. Andrade, E.N.da.C. 1914 The flow in metals under large constant stresses. Proc. R. Soc. A 90, 329. Bailey, R. W. 1929 Creep of steel under simple and compound stress and the use of high initial temperature in steam power plants. Trans World Power Conference Tokyo 3, 1089.

Bailey, R. W. 1935 The utilisation of creep test data in engineering design. Proc. IMechE 131, 260. 
British Energy Generation Ltd. 2001 An assessment procedure for the high-temperature response of structures, R5 Issue 2, Revision 2.

British Standards Institution 1989 Specification for design and manufacture of water-tube steam generating plant (including superheaters, reheaters and steel tube economisers), BS 1113:1989.

British Standards Institution 1991 Specification for unfired fusion welded pressure vessels, $B S$ 5500:1991.

British Standards Institution 1993 Specification for design and construction of ferrous piping installations for and in connection with land boilers, BS 806:1993.

Cane, B. J. 1981 Creep fracture of dispersion strengthened low alloy ferritic steels. Acta Metall. 29, 1581. (doi:10.1016/0001-6160(81)90040-7.)

Chaboche, J. L. 1999 Creep and damage in materials and structures. In CISM Course and Lecture No. 399, International Centre for Mechanical Sciences (ed. H. Altenbach \& J. J. Skrzypek), pp. 209-293. New York: Springer Wien.

Coleman, M. C., Parker, J. D. \& Walters, D. J. 1985 The behaviour of ferritic weldments in thick section $0.5 \mathrm{Cr} 0.5 \mathrm{Mo} 0.25 \mathrm{~V}$ pipe at elevated temperature. Int. J. Press. Vessels Piping 18, 277. (doi:10.1016/0308-0161(85)90015-8.)

Dyson, B. F. \& Gibbons, T. B. 1987 Tertiary creep in nickel-based superalloys: analysis of experimental data and theoretical synergies. Acta Metall. 35, 2355. (doi:10.1016/00016160(87)90083-6.)

Dyson, B. F. \& Mclean, M. 2000 The role of micromechanisms quantification in developing creep constitutive equations. In. Proc. 5th IUTAM Symp. on Creep in Structures. Nagoya, Japan, pp. 3-16. Kluwer: Academic Press.

Flewitt, P. E. J., Browne, R. J., Lonsdale, D., Shammas, M. S. \& Soo, J. N. 1989 Multiaxial stress in relationship to creep life: evaluation of testing procedures, preliminary assessment of multiaxial stress criterion and strategy for testing. CEGB report OED/STB(S)/88?0033/R.

Garofalo, F. 1963 Emperical relation defining stress dependence of minimum creep rate in metals. Trans. AIME 227, 351.

Gooch, D. J. \& Kimmins, S. T. 1987 Type IV cracking in $0.5 \mathrm{Cr} 0.5 \mathrm{Mo} 0.25 \mathrm{~V} / 2.25 \mathrm{Cr} 1 \mathrm{Mo}$ weldments. In Proc. Third Int. Conf. on Creep and Fatigue of Engineering Materials and Structure, Swansea (ed. B. Wilshire \& R. W. Evans).

Hall, F. R. \& Hayhurst, D. R. 1991 Continuum damage mechanics modeling of high-temperature deformation and failure in a pipe weldment. Proc. R. Soc. A 433, 383.

Hayhurst, D. R. 1972 Creep rupture under multiaxial states of stress. J. Mech. Phys. Solids 20, 381. (doi:10.1016/0022-5096(72)90015-4.)

Hayhurst, D. R. \& Miller, D. A. 1998 The use of creep continuum damage mechanics to predict damage evolution and failure in welded vessels. IMechE S539/008, 117.

Hayhurst, D. R. \& Perrin, I. J. 1995 CDM analysis of creep rupture in weldments The ASCE Engineering Mechanics Conference, Boulder, Colorado, USA, May 1995. Published in Proc. ASCE, vol. 1, pp. 393-396.

Hayhurst, D. R., Dimmer, P. R. \& Chernuka, M. W. 1975 Estimates of the creep rupture lifetime of structures using the finite element method. J. Mech. Phys. Solids 23, 335. (doi:10.1016/00225096(75)90032-0.)

Hayhurst, D. R., Dimmer, P. R. \& Morrison, C. J. 1984 Development of continuum damage in the creep rupture of notched bars. Phil. Trans. R. Soc. A 311, 103.

Kowalewski, Z. L., Hayhurst, D. R. \& Dyson, B. F. 1994 Mechanisms based creep constitutive equations for an aluminium alloy. J. Strain Anal. 29, 309-316.

Leckie, F. A. \& Hayhurst, D. R. 1974 Creep rupture of structures. Proc. R. Soc. A 340, 323.

Lemaitre, J. 1992 A course on damage mechanics. Berlin: Springer ch. 2.

Lemaitre, J. \& Chaboche, I. L. 1990 Mechanics of solid materials. Cambridge: Cambridge University Press ch. 2.

Norton, F. H. 1929 Creep of steel at high temperatures. New York: Mc Graw-Hill.

Odqvist, F. K. G. 1934 Creep stresses in a rotating disc. Proc. IV Int. Congress for Applied Mechanics, Cambridge, p. 228. 
Odqvist, F. K. G. 1974 Mathematical theory of creep and creep rupture Oxford Mathematical Monographs, 2nd edn. Oxford: Clarendon Press.

Othman, A. M., Hayhurst, D. R. \& Dyson, B. F. 1993 Skeletal point stress in circumferentially notched tension bars undergoing tertiary creep modelled with physically based constitutive equations. Proc. R. Soc. A 441, 343.

Perrin, I. J 1995 Computer-based Type IV creep CDM design of low alloy ferritic steel weldments. Ph.D. thesis, UMIST.

Perrin, I. J. \& Hayhurst, D. R. $1994 a$ Physically based creep constitutive equations for a $0.5 \mathrm{Cr}$ 0.5Mo $0.25 \mathrm{~V}$ ferritic steel at $635^{\circ} \mathrm{C}$. UMIST Department of Mechanical Engineering Internal Report DMM.94.23.

Perrin, I. J. \& Hayhurst, D. R. $1994 b$ A method for the extrapolation of creep constitutive equations to represent the behaviour at different temperatures and of different materials within the same domain. UMIST Department of Mechanical Engineering Internal Report DMM.94.24.

Perrin, I. J. \& Hayhurst, D. R. 1994c Computational damage modelling of multiaxial creep tests to determine the multiaxial stress criteria for a $0.5 \mathrm{Cr} 0.5 \mathrm{Mo} 0.25 \mathrm{~V}$ ferritic steel. UMIST Department of Mechanical Engineering Internal Report DMM.94.25.

Perrin, I. J. \& Hayhurst, D. R. 1996 a A method for the transformation of creep constitutive equations. Int. J. Press. Vessels Piping 68, 299. (doi:10.1016/0308-0161(95)00069-0.)

Perrin, I. J. \& Hayhurst, D. R. $1996 b$ Creep constitutive equations for a $0.5 \mathrm{Cr} 0.5 \mathrm{Mo} 0.25 \mathrm{~V}$ ferritic steel in the temperature range $600-675^{\circ}$ C. J. Strain Anal. 31, 299.

Perrin, I. J. \& Hayhurst, D. R. 1999 Continuum damage mechanics analyses of Type IV creep failure in ferritic steel crossweld specimens. Int. J. Press. Vessels Piping 76, 599. (doi:10.1016/ S0308-0161(99)00051-4.)

Perrin, I. J., Hayhurst, D. R. \& Ainsworth, R. A. 2000 Approximate creep rupture lifetimes for butt welded ferritic steel pressurised pipes. Eur. J. Mech. A/Solids 19, 223. (doi:10.1016/S09977538(00)00160-1.)

Wang, Z. P. \& Hayhurst, D. R. 1994 The use of supercomputer modeling of high-temperature failure in pipe weldments to optimise weld and heat affected zone materials property selection. Proc. R. Soc. A 446, 127. 